Cochrane Database of Systematic Reviews

\title{
Metformin treatment before and during IVF or ICSI in women with polycystic ovary syndrome (Review)
}

Tso LO, Costello MF, Albuquerque LET, Andriolo RB, Macedo CR

Tso LO, Costello MF, Albuquerque LET, Andriolo RB, Macedo CR.

Metformin treatment before and during IVF or ICSI in women with polycystic ovary syndrome.

Cochrane Database of Systematic Reviews 2014, Issue 11. Art. No.: CD006105.

DOI: 10.1002/14651858.CD006105.pub3.

www.cochranelibrary.com 
TABLE OF CONTENTS

HEADER 1

ABSTRACT

PLAIN LANGUAGE SUMMARY

SUMMARY OF FINDINGS

BACKGROUND

OBJECTIVES

METHODS

RESULTS

Figure 1.

Figure 2.

Figure 3.

Figure 4.

Figure 5.

Figure 6.

DISCUSSION

AUTHORS' CONCLUSIONS

ACKNOWLEDGEMENTS

REFERENCES

CHARACTERISTICS OF STUDIES

DATA AND ANALYSES

Analysis 1.1. Comparison 1 Metformin versus placebo or no treatment, Outcome 1 Live birth rate per woman. ......................

Analysis 1.2. Comparison 1 Metformin versus placebo or no treatment, Outcome 2 Clinical pregnancy rate per woman. .........

Analysis 1.3. Comparison 1 Metformin versus placebo or no treatment, Outcome 3 Incidence of OHSS per woman. ................

Analysis 1.4. Comparison 1 Metformin versus placebo or no treatment, Outcome 4 Miscarriage rate per woman. ....................

Analysis 1.5. Comparison 1 Metformin versus placebo or no treatment, Outcome 5 Side effects per woman.

Analysis 1.6. Comparison 1 Metformin versus placebo or no treatment, Outcome 6 Number of oocytes retrieved per woman. ..

Analysis 1.7. Comparison 1 Metformin versus placebo or no treatment, Outcome 7 Mean total dose of FSH (IU) per woman. ....

Analysis 1.8. Comparison 1 Metformin versus placebo or no treatment, Outcome 8 Mean days of gonadotrophin per woman. ..

Analysis 1.9. Comparison 1 Metformin versus placebo or no treatment, Outcome 9 Cycle cancellation rate (after ovulation induction).

Analysis 1.10. Comparison 1 Metformin versus placebo or no treatment, Outcome 10 Serum oestradiol level (nmol/ l) per woman.

Analysis 1.11. Comparison 1 Metformin versus placebo or no treatment, Outcome 11 Mean or median serum androgen levels per woman.

Analysis 1.12. Comparison 1 Metformin versus placebo or no treatment, Outcome 12 Mean or median fasting insulin and glucose levels per woman.

APPENDICES

WHAT'S NEW

HISTORY

CONTRIBUTIONS OF AUTHORS

DECLARATIONS OF INTEREST

SOURCES OF SUPPORT

DIFFERENCES BETWEEN PROTOCOL AND REVIEW

INDEX TERMS 
[Intervention Review]

\section{Metformin treatment before and during IVF or ICSI in women with polycystic ovary syndrome}

Leopoldo O Tsoㄹ, Michael F Costello², Luiz Eduardo T Albuquerque ${ }^{3}$, Régis B Andriolo ${ }^{4}$, Cristiane R Macedo 5

1Gynecology, Universidade Federal de São Paulo, São Paulo, Brazil. 2Division of Obstetrics \& Gynaecology, School of Women's \& Children's Health, Royal Hospital for Women and IVF Australia, Sydney, Australia. ${ }^{3}$ Human Reproduction Center, Fertivitro Centro de Reprodução Humana, São Paulo, Brazil. ${ }^{4}$ Department of Public Health, Universidade do Estado do Pará, Belém, Brazil. ${ }^{5}$ Brazilian Cochrane Centre, Centro de Estudos de Saúde Baseada em Evidências e Avaliação Tecnológica em Saúde, São Paulo, Brazil

Contact address: Leopoldo O Tso, Gynecology, Universidade Federal de São Paulo, Av. Dr. Altino Arantes, 865. Ap. 124, Vila Clementino, São Paulo, São Paulo, 04042-034, Brazil. leotso@uol.com.br.

Editorial group: Cochrane Gynaecology and Fertility Group

Publication status and date: Edited (no change to conclusions), published in Issue 4, 2015.

Citation: Tso LO, Costello MF, Albuquerque LET, Andriolo RB, Macedo CR. Metformin treatment before and during IVF or ICSI in women with polycystic ovary syndrome. Cochrane Database of Systematic Reviews 2014, Issue 11. Art. No.: CD006105. DOI: 10.1002/14651858.CD006105.pub3.

Copyright (c) 2015 The Cochrane Collaboration. Published by John Wiley \& Sons, Ltd.

\section{A B S T R A C T}

\section{Background}

The use of insulin-sensitising agents, such as metformin, in women with polycystic ovary syndrome (PCOS) who are undergoing ovulation induction or in vitro fertilisation (IVF) cycles has been widely studied. Metformin reduces hyperinsulinaemia and suppresses the excessive ovarian production of androgens. As a consequence, it is suggested that metformin could improve assisted reproductive techniques (ART) outcomes, such as ovarian hyperstimulation syndrome (OHSS), pregnancy and live birth rates.

\section{Objectives}

To determine the effectiveness and safety of metformin as a co-treatment during IVF or intracytoplasmic sperm injection (ICSI) in achieving pregnancy or live birth in women with PCOS.

\section{Search methods}

We searched the Cochrane Menstrual Disorders and Subfertility Group Trials Register, Cochrane Central Register of Controlled Trials (CENTRAL) (The Cochrane Library), MEDLINE, EMBASE, LILACS, the metaRegister of Controlled Trials and reference lists of articles (up to 15 October 2014).

\section{Selection criteria}

Types of studies: randomised controlled trials (RCTs) comparing metformin treatment with placebo or no treatment in women with PCOS who underwent IVF or ICSI treatment.

Types of participants: women of reproductive age with anovulation due to PCOS with or without co-existing infertility factors.

Types of interventions: metformin administered before and during IVF or ICSI treatment.

Types of outcome measures: live birth rate, clinical pregnancy rate, miscarriage rate, incidence of ovarian hyperstimulation syndrome , incidence of participant-reported side effects, serum oestradiol level on the day of trigger, serum androgen level, and fasting insulin and glucose levels. 


\section{Data collection and analysis}

Two review authors independently selected the studies, extracted the data according to the protocol and assessed study quality. The overall quality of the evidence was assessed using GRADE methods.

\section{Main results}

We included nine randomised controlled trials involving a total of 816 women with PCOS. When metformin was compared with placebo there was no clear evidence of a difference between the groups in live birth rates (OR $1.39,95 \% \mathrm{Cl} 0.81$ to 2.40 , five RCTs, 551 women, $\mathrm{I}^{2}=52 \%$, low-quality evidence). Our findings suggest that for a woman with a $32 \%$ chance of achieving a live birth using placebo, the corresponding chance using metformin treatment would be between $28 \%$ and $53 \%$.

When metformin was compared with placebo or no treatment, clinical pregnancy rates were higher in the metformin group (OR 1.52;95\% $\mathrm{Cl}$ 1.07 to 2.15; eight RCTs, 775 women, $12=18 \%$, moderate-quality evidence). This suggests that for a woman with a $31 \%$ chance of achieving a clinical pregnancy using placebo or no treatment, the corresponding chance using metformin treatment would be between $32 \%$ and $49 \%$.

The risk of ovarian hyperstimulation syndrome was lower in the metformin group (OR $0.29 ; 95 \% \mathrm{Cl} 0.18$ to 0.49 , eight RCTs, 798 women, I2 $=11 \%$, moderate-quality evidence). This suggests that for a woman with a $27 \%$ risk of having OHSS without metformin the corresponding chance using metformin treatment would be between $6 \%$ and $15 \%$.

Side effects (mostly gastrointestinal) were more common in the metformin group (OR 4.49, 95\% Cl 1.88 to 10.72 , for RCTs, 431 women, $12=57 \%$, low quality evidence)

The overall quality of the evidence was moderate for the outcomes of clinical pregnancy, OHSS and miscarriage, and low for other outcomes. The main limitations in the evidence were imprecision and inconsistency.

\section{Authors' conclusions}

This review found no conclusive evidence that metformin treatment before or during ART cycles improved live birth rates in women with PCOS. However, the use of this insulin-sensitising agent increased clinical pregnancy rates and decreased the risk of OHSS.

\section{PLAIN LANGUAGE SUMMARY}

\section{Metformin in women with polycystic ovary syndrome for improving fertility}

Review question: The aim of this Cochrane review was to determine the effectiveness and safety of metformin, an insulin-sensitising agent, for improving ART outcomes, especially, live birth and clinical pregnancy rates, in women with PCOS undergoing in vitro fertilisation (IVF) treatment.

Background: Polycystic ovary syndrome (PCOS) is a condition characterised by chronic failure or absence of ovulation (anovulation) and excessive production of male hormones (hyperandrogenism). The main symptoms of this disorder are irregular menstrual cycles, infertility, hirsutism (excessive hair growth) and acne. This condition is the most common endocrine disorder in women, affecting approximately $5 \%$ to $10 \%$ of all women of reproductive age.

Study characteristics: The review included nine randomised controlled trials involving a total of 816 women who were randomised to receive metformin (411) versus placebo or no treatment (405). The trials were conducted in the Czech Republic, Italy, Jordan, Norway, Turkey and the United Kingdom. The evidence is current to October 2014.

Key results: When metformin was compared with placebo or no treatment, there was no conclusive evidence of a difference between the groups in live birth rates, but pregnancy rates were higher in the metformin group, and the risk of OHSS was lower. We estimated that for a woman with a $32 \%$ chance of achieving a live birth using placebo, the corresponding chance using metformin would be between $28 \%$ and $53 \%$. For a woman with a $31 \%$ chance of achieving a clinical pregnancy without metformin, the corresponding chance using metformin would be between $32 \%$ and $49 \%$. For a woman with a $27 \%$ risk of ovarian hyperstimulation syndrome (OHSS) without metformin, the corresponding chance using metformin would be between $6 \%$ and $15 \%$. Side effects (mostly gastrointestinal) were more common in the metformin group, though only four studies reported this outcome.

Quality of the evidence: The overall quality of the evidence was moderate for the outcomes of clinical pregnancy, OHSS and miscarriage, and low for other outcomes. The main limitations in the evidence were imprecision and inconsistency.

Conclusion: We found no conclusive evidence that metformin treatment before or during ART cycles improved live birth rates in women with PCOS. However, the use of this insulin-sensitising agent increased clinical pregnancy rates and decreased the risk of OHSS. 
SUMMARY OF FINDINGS

Summary of findings for the main comparison. Metformin treatment before and during IVF or ICSI for women with polycystic ovary syndrome

Metformin treatment before or during IVF or ICSI for women with polycystic ovary syndrome

Population: Women with polycystic ovary syndrome

Settings: Assisted reproduction

Intervention: Metformin treatment before or during IVF or ICSI

Control: Placebo or no treatment

\begin{tabular}{|c|c|c|c|c|c|c|}
\hline \multirow[t]{3}{*}{ Outcomes } & \multicolumn{2}{|c|}{ Illustrative comparative risks $(95 \% \mathrm{CI})$} & \multirow{3}{*}{$\begin{array}{l}\text { Relative effect } \\
(95 \% \mathrm{Cl})\end{array}$} & \multirow{3}{*}{$\begin{array}{l}\text { No of Partici- } \\
\text { pants } \\
\text { (studies) }\end{array}$} & \multirow{3}{*}{$\begin{array}{l}\text { Quality of the } \\
\text { evidence } \\
\text { (GRADE) }\end{array}$} & \multirow[t]{3}{*}{ Comments } \\
\hline & Assumed risk & Corresponding risk & & & & \\
\hline & $\begin{array}{l}\text { Placebo or no } \\
\text { treatment }\end{array}$ & Metformin treatment & & & & \\
\hline $\begin{array}{l}\text { Live birth rate (per woman) - ITT } \\
\text { Delivery of one or more living in- } \\
\text { fants/pregnancy beyond } 20 \text { weeks } \\
\text { of gestation. }\end{array}$ & 320 per 1000 & $\begin{array}{l}395 \text { per } 1000 \\
(276 \text { to } 530)\end{array}$ & $\begin{array}{l}\text { OR } 1.39 \\
\text { (0.81 to } 2.40)\end{array}$ & $\begin{array}{l}551 \\
\text { (5 studies) }\end{array}$ & $\begin{array}{l}\oplus \oplus \odot \odot \\
\text { low } 1,2,4\end{array}$ & \\
\hline $\begin{array}{l}\text { Clinical pregnancy rate (per } \\
\text { woman) - ITT } \\
\text { Identified by the presence of a ges- } \\
\text { tational sac on ultrasonography }\end{array}$ & 307 per 1000 & $\begin{array}{l}403 \text { per } 1000 \\
\text { (322 to } 488)\end{array}$ & $\begin{array}{l}\text { OR 1.52 } \\
\text { (1.07 to } 2.15)\end{array}$ & $\begin{array}{l}775 \\
\text { (8 studies) }\end{array}$ & $\begin{array}{l}\oplus \oplus \oplus \ominus \\
\text { moderate } 2,4\end{array}$ & \\
\hline Incidence of OHSS & 270 per 1000 & $\begin{array}{l}97 \text { per } 1000 \\
\text { (62 to } 153)\end{array}$ & $\begin{array}{l}\text { OR } 0.29 \\
\text { (0.18 to } 0.49)\end{array}$ & $\begin{array}{l}798 \\
\text { (8 studies) }\end{array}$ & $\begin{array}{l}\oplus \oplus \oplus \ominus \\
\text { moderate }^{2}\end{array}$ & \\
\hline Miscarriage rate (per woman) & 139 per 1000 & $\begin{array}{l}110 \text { per } 1000 \\
(65 \text { to } 182)\end{array}$ & $\begin{array}{l}\text { OR } \mathbf{0 . 7 6} \\
\text { (0.43 to } 1.37 \text { ) }\end{array}$ & $\begin{array}{l}521 \\
\text { (6 studies) }\end{array}$ & $\begin{array}{l}\oplus \oplus \oplus \ominus \\
\text { moderate } 2\end{array}$ & \\
\hline Side effects & 106 per 1000 & $\begin{array}{l}347 \text { per } 1000 \\
(182 \text { to } 559)\end{array}$ & $\begin{array}{l}\text { OR } 4.49 \\
(1.88 \text { to } 10.72)\end{array}$ & $\begin{array}{l}431 \\
\text { (4 studies) }\end{array}$ & $\begin{array}{l}\oplus \oplus \ominus \ominus \\
\text { low } 1,3\end{array}$ & \\
\hline
\end{tabular}

*The basis for the assumed risk is the median control group risk across studies. The corresponding risk (and its $95 \%$ confidence interval) is based on the assumed risk in

the comparison group and the relative effect of the intervention (and its $95 \% \mathrm{CI}$ ).

Cl: Confidence interval; OR: Odds ratio;

GRADE Working Group grades of evidence

High quality: Further research is very unlikely to change our confidence in the estimate of effect. 
Moderate quality: Further research is likely to have an important impact on our confidence in the estimate of effect and may change the estimate.

Low quality: Further research is very likely to have an important impact on our confidence in the estimate of effect and is likely to change the estimate.

Very low quality: We are very uncertain about the estimate.

1 Inconsistency: unexplained heterogeneity $(12=52 \%)$

2 Imprecision: total number of events is fewer than 300

3 Inconsistency: unexplained heterogeneity $(12=57 \%)$

4There was a data discrepancy in one of these studies (Palombo 2011). According to the study publication, in both the metformin group and the placebo group the clinical

pregnancy rate was lower than the live birth rate. Sensitivity analyses excluding this study yielded an OR of $1.48(95 \% \mathrm{Cl} 0.72$ to 3.02$)$ for live birth and 1.61 (95\% $\mathrm{Cl} 1.08$ to 2.40$)$

for pregnancy, which did not substantially change our findings. 


\section{B A C K G R O U N D}

\section{Description of the condition}

Polycystic ovary syndrome (PCOS) is a disorder characterised by chronic anovulation (failure or absence of ovulation) and hyperandrogenism (excessive production of male hormones in women) and is associated with irregular menstrual cycles, infertility, hirsutism and acne (Speroff 1995). This condition is the most common endocrine disorder in women, affecting approximately $5 \%$ to $10 \%$ of all women of reproductive age (Frank 1995; Knochenhauer 1998).

PCOS is a heterogenous condition, from a clinical as well as from a biochemical perspective. According to the recommendations proposed by an international consensus group (ESHRE/ASRM 2003), the diagnosis of PCOS is made when at least two of the following criteria are met:

1. oligo- or anovulation (infrequent or no ovulation);

2. clinical or biochemical signs of hyperandrogenism, or both;

3. polycystic ovaries on ultrasound.

Other causes of hyperandrogenism that mimic PCOS (such as congenital adrenal hyperplasia, Cushing's syndrome or androgensecreting tumours) should have been excluded.

Although the primary aetiology of PCOS is unknown (Balen 2004), insulin resistance with compensatory hyperinsulinaemia is a prominent feature of the syndrome and seems to play an important physiopathological role in hyperandrogenism, both in lean and obese women with PCOS (Dunaif 1989; Tsilchorozidou 2004). Hyperinsulinaemia increases ovarian androgen biosynthesis, both in vivo and in vitro (Adashi 1985; Barbieri 1986), and decreases the hepatic production of sex hormone-binding globulin (SHBG) (Nestler 1991) thus leading to increased bioavailability of free androgens.

\section{Description of the intervention}

Several treatments have been used to induce ovulation and pregnancy in infertile anovulatory women with PCOS. The use of clomiphene citrate as first-line treatment leads to modest pregnancy rates (Barbieri 2000; Kocak 2002; Thessaloniki ESHRE/ ASRM-Sponsored PCOS 2008). Based on the association between insulin resistance and anovulation in PCOS participants, insulinsensitising agents, such as metformin, have been recently added to the treatment protocols of these women (Costello 2007; Nestler 2002; Jungheim 2010).

\section{How the intervention might work}

Metformin is an orally active, water-soluble biguanide used for the treatment type 2 diabetes mellitus. The drug has an antihyperglycaemic effect and does not cause hypoglycaemia. It enhances insulin sensitivity both in the liver, by inhibiting hepatic glucose production, and in peripheral tissues, such as muscle cells, by increasing glucose uptake and utilisation (Barbieri 1986; Dunn 1995; Nardo 2001). There is a good physiological rationale for believing that suppression of insulin levels, through the use of insulin-sensitising agents such as metformin, may be useful in women with PCOS who are undergoing in vitro fertilisation (IVF) with or without intracytoplasmic sperm injection (ICSI). Suppression of insulin levels might ameliorate the adverse effects of ovarian stimulation and improve treatment outcomes such as ovulation and pregnancy rates (Dunaif 1989; Tang 2006). In addition, metformin may also act directly on ovarian thecal cells, decreasing androgen production (Attia 2001; Palomba 2010).

\section{Why it is important to do this review}

Women with PCOS who are undergoing ovarian stimulation with follicle-stimulating hormone (FSH) are considered to be at increased risk for ovarian hyperstimulation syndrome (OHSS), one of the most important complications of assisted reproductive technology (ART). Higher total FSH doses lead to a larger number of follicles and oocytes, high serum oestradiol (E2) levels, increased risk of OHSS, elevated cancellation rates and lower conception rates (Aboulghar 2003; Yarali 2004). Therefore it is important to assess the effects of metformin on the clinical, biochemical and laboratory profiles of PCOS women undergoing ART cycles. Several adequately designed trials have addressed this question (Kjotrod 2004; Kjotrod 2011; Palomba 2011; Tang 2006).

\section{O B J E C T IVES}

To determine the effectiveness and safety of metformin as a cotreatment during IVF or intracytoplasmic sperm injection (ICSI) in achieving pregnancy or live birth in women with PCOS.

\section{METHODS}

\section{Criteria for considering studies for this review \\ Types of studies}

The review included randomised controlled trials (RCTs) comparing metformin treatment with placebo or no treatment in women with PCOS undergoing IVF or ICSI treatment.

Quasi-randomised trials were not included. Only the first part of cross-over trials was considered in the meta-analysis.

\section{Types of participants}

Women of reproductive age with anovulation attributed to PCOS, with or without another cause of couple infertility, who were treated with metformin before and during an IVF or ICSI cycle were eligible.

The aetiology of infertility leading to treatment by IVF or ICSI was defined by individual study authors. The diagnosis of PCOS was based on the ESHRE/ASRM criteria (ESHRE/ASRM 2003). Due to the wide variation of diagnostic criteria used for PCOS, studies that used different diagnostic criteria were included in the review if the broad definition included in the study matched the ESHRE/ ASRM criteria. According to the recommendations proposed by that group, the diagnosis of PCOS is made when at least two of the following criteria are met:
1. oligo- or anovulation (infrequent or no ovulation);
2. clinical or biochemical (or both) signs of hyperandrogenism;
3. polycystic ovaries on ultrasound.

Other causes of hyperandrogenism that mimic PCOS (such as congenital adrenal hyperplasia, Cushing's syndrome or androgensecreting tumours) should have been excluded. 


\section{Types of interventions}

Metformin versus no treatment or placebo before or during IVF or ICSI treatment.

\section{Types of outcome measures}

\section{Primary outcomes}

1. Live birth rate (per woman), defined as a baby born after 20 weeks of gestation.

2. Clinical pregnancy rate (per woman), defined as the identification of an intrauterine gestational sac on ultrasound scan.

3. Incidence of OHSS (per woman), defined according to the definition of reporting authors.

\section{Secondary outcomes}

4. Miscarriage rate (per woman), defined as the involuntary loss of a pregnancy before 20 weeks gestation.

5. Incidence of participant-reported side effects.

6. Number of oocytes retrieved.

7. Total dose of FSH (in IU).

8. Number of days of gonadotrophin treatment.

9. Cycle cancellation rate (per woman).

10. Serum oestradiol level on the day of human chorionic gonadotrophin (hCG) trigger injection.

11. Serum androgen level (total testosterone, sex hormone-binding globulin (SHBG) or free-androgen index).

12. Fasting insulin and glucose levels.

13. Fertilisation rate, defined as normal fertilisation with two pronuclei-stage embryos. The fertilisation rate was defined as the number of normally fertilised oocytes divided by the number of oocytes retrieved per cycle.

\section{Search methods for identification of studies}

We sought all relevant RCTs of metformin co-treatment (prior to or during ovarian stimulation) in women with PCOS undergoing IVF or ICSI treatment, without language restriction. Searching was originally done in 2008 . We carried out updated searches in November 2012, September 2013 and 15 October 2014. Our searches were performed in consultation with the Cochrane Menstrual Disorders and Subfertility Group Trials Search Coordinator.

\section{Electronic searches}

For the identification of relevant studies, we developed detailed search strategies for each specific database. These were based on the search strategy developed for MEDLINE (OVID) and revised appropriately for each database. We searched the following databases: Cochrane Menstrual Disorders and Subfertility Group Trials Register (searched 15 October 2014), Cochrane Central Register of Controlled Trials (CENTRAL) (The Cochrane Library 2014, Issue 10), MEDLINE (1966 to October 2014), EMBASE (1980 to October 2014) and LILACS (1982 to October 2014). We also searched trial registers for ongoing and registered trials: http://www.controlled-trials.com; http://clinicaltrials.gov/ ct2/home; http://www.who.int/trialsearch/Default.aspx. Search details are available in Appendix 1 (October 2014).

\section{Searching other resources}

We checked the citation lists of relevant publications, review articles and included studies. We handsearched references of identified selected articles for additional relevant citations. We also contacted experts in the field for additional relevant citations.

\section{Data collection and analysis}

We analysed data using Review Manager 5.1 (RevMan 2011).

\section{Selection of studies}

For the 2014 update, two authors (LOT and LETA) independently selected the trials included in this review in accordance with the aforementioned criteria. Disagreements were settled by a third review author (CRM). Particular attention was paid to whether there were differences in the characteristics of the women in the comparison groups as to:

- age;

- body mass index (BMI);

- duration and causes of infertility;

- dose and duration of metformin co-treatment;

- androgen levels (total testosterone, SHBG, free-androgen index);

- fasting glucose and insulin levels;

- number of embryos transferred;

- previous ovarian surgery.

\section{Data extraction and management}

Two authors (LOT and LETA) extracted all data independently using forms designed according to Cochrane guidelines. We sought additional information from authors of trials that appeared to meet the eligibility criteria but had unclear methodological details. We also sought further trial data when the data in the reports were presented in a form that was unsuitable for meta-analysis.

Differences of opinion were registered and resolved by consensus. The review authors planned to perform a series of analyses on the results. These analyses were not always possible due to an insufficient number of trials reporting on a particular outcome.

We extracted the following information from the studies included in the review and this is presented in the Characteristics of included studies table.

1. Trial characteristics

a. Randomisation

b. Allocation concealment

c. Trial design: multicentre or single centre, single phase or cross-over design

d. Number of participants randomised, excluded and analysed

e. Duration, timing and location of the trial

f. Source of funding 
2. Baseline characteristics of the studied groups
a. Definition of PCOS and duration of pre-existing infertility
b. Age of the participants
c. Investigative work-up
d. Other causes of infertility
e. Previously administered infertility treatment(s)
f. BMI

3. Interventions
a. Type of intervention and control
b. Dose regimen and duration

4. Outcomes
a. Outcomes reported
b. Definition of outcomes
c. Measurement of outcomes
d. Timing of outcome measurement

\section{Assessment of risk of bias in included studies}

Two review authors (LEO and CRM) independently assessed the risk of bias of the included studies using the tools described in Chapter 8 of the Cochrane Handbook for Systematic Reviews of Interventions version 5.1.0 (Higgins 2011). The domains investigated were: allocation (random sequence generation and allocation concealment); blinding of participants, personnel and outcome assessors; completeness of outcome data; selective reporting and other biases.

\section{Measures of treatment effect}

For dichotomous data, we expressed the results for each study as odds ratios (ORs) with 95\% confidence intervals (Cls). For continuous data, we measured the mean post-treatment intervention values and standard deviations for each group and calculated mean differences (MDs) with $95 \% \mathrm{Cls}$. If similar outcomes were reported using different scales, we calculated the standard mean differences (SMDs) with 95\% Cls.

\section{Unit of analysis issues}

We analysed the primary outcomes and the miscarriage outcomes per woman randomised. Some of the included studies reported our primary outcomes using other units of analysis (e.g. per cycle, per embryo transfer). These data were not included in the review because they were not randomised comparisons but applied only to selected subsets of participants, such as those who underwent repeated cycles or those who underwent embryo transfer.

We reported and pooled the review outcomes number of gonadotrophin units used and number of days of gonadotrophin treatment, because all women underwent one treatment cycle. For studies that performed more than one cycle per woman, only the data from the first cycle were included in the meta-analyses.

\section{Dealing with missing data}

As far as possible, we analysed data on an intention-to-treat (ITT) basis and made attempts to obtain missing data from the original trials. Where data were unavailable, we only analysed the available data.

\section{Assessment of heterogeneity}

We considered whether the clinical and methodological characteristics of the included studies were sufficiently similar for meta-analysis to provide a clinically meaningful summary. We assessed statistical heterogeneity using the $I^{2}$ statistic; $\left.\right|^{2}>50 \%$ was interpreted as being indicative of substantial heterogeneity among studies.

\section{Assessment of reporting biases}

In view of the difficulty of detecting and correcting for publication bias and other reporting biases, we aimed to minimise their potential impact by undertaking a comprehensive search for eligible studies and by paying attention to data duplication. We planned to use a funnel plot to explore the possibility of publication bias, if enough studies (10 or more) were found for any of the primary analyses.

\section{Data synthesis}

We combined data for meta-analysis with the RevMan software using a random-effects model. For reporting purposes we translated primary outcomes to absolute risks.

\section{Subgroup analysis and investigation of heterogeneity}

We performed a stratified meta-analysis according to the type of stimulation protocol (long GnRH-agonist or short GnRHantagonist). This stratification was added in the 2014 update of the review, to examine any possible difference in effect related to type of stimulation.

If there was a clinically important difference in drug regimen (outside normal clinical practice) among studies, we planned to examine the possible effects by performing subgroup analyses.

\section{Sensitivity analysis}

We conducted sensitivity analyses for the primary outcomes to determine whether the conclusions were robust to arbitrary decisions made regarding the eligibility and analysis. These analyses included consideration of whether the review conclusions would have differed if:

1. Eligibility were restricted to studies without high risk of bias.

2. A fixed effect model had been adopted

3. The summary effect measure had been relative risk rather than odds ratio.

\section{Overall quality of the body of evidence: 'Summary of findings' table}

We generated a 'Summary of findings' table using GRADEpro 2011 software. This table evaluated the overall quality of the body of evidence for main review outcomes, using GRADE criteria (study limitations i.e. risk of bias, consistency of effect, imprecision, indirectness and publication bias). Judgements about evidence quality (high, moderate or low) were justified, documented and incorporated into the reporting of results for each outcome. 


\section{RES U L T S}

\section{Description of studies}

\section{Results of the search}

The 2014 search retrieved 185 citations. After screening the titles and abstracts of these citations, we selected 25 for full-text reading, of which we excluded 15. One study (Tang 2010) is awaiting classification and nine matched the selection criteria and were included in the review (see Figure 1 for details of the study selection process). There were three duplicate publications: Stadtmauer 1999 and Stadtmauer 2000, the latter being a continuation of the former; Visnova 2002 and Visnova 2003, one in English and the other in Czech; Kjotrod 2003a, Kjotrod 2004 and Kjotrod 2008a, all generated from the same trial. 
Figure 1. Study flow diagram.

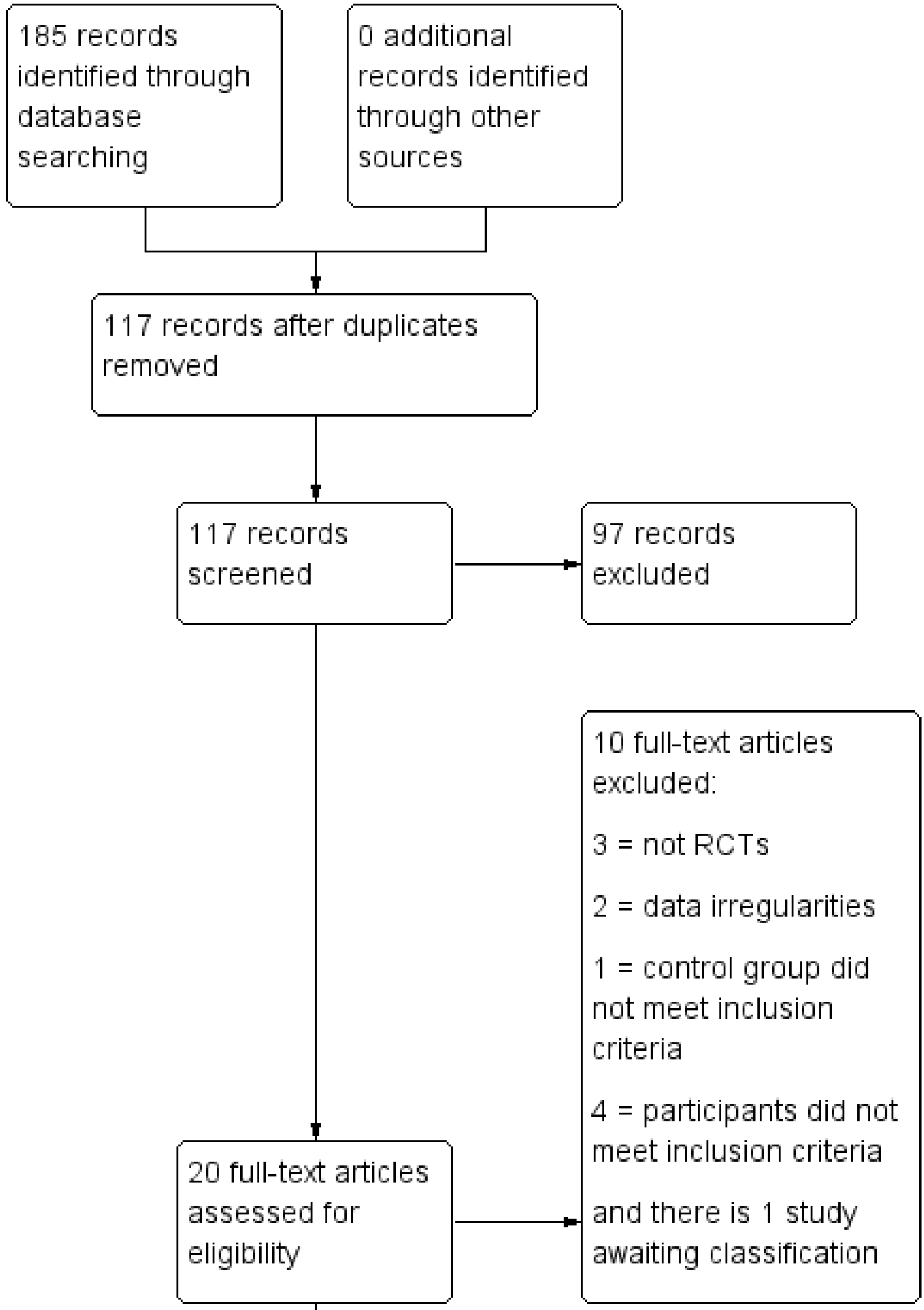


Figure 1. (Continued)

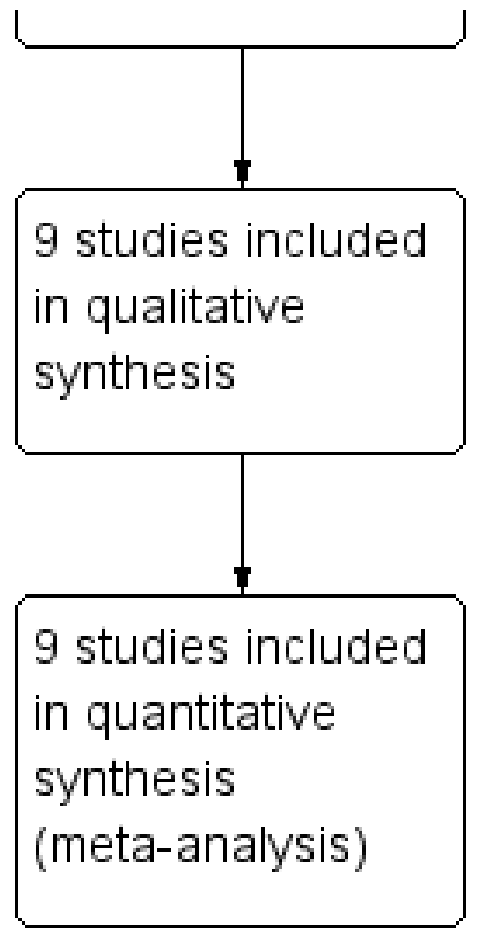

Three new studies were included in this updated version of the 2009 systematic review (Kjotrod 2011; Palomba 2011; Qublan 2009). Therefore nine studies in total met the inclusion criteria and were included in the review (Doldi 2006; Fedorcsak 2003; Kjotrod 2004; Kjotrod 2011; Onalan 2005; Palomba 2011; Qublan 2009; Tang 2006; Visnova 2003). We sent emails to the authors of three studies to obtain more details on study characteristics and methodological quality that were unclear in the published article. Three author groups (Fedorcsak 2003; Onalan 2005; Tang 2006) answered our queries. See the tables Characteristics of included studies and Characteristics of excluded studies. All trials reported that only one cycle per participant was permitted, with the exception of Fedorcsak 2003 (a cross-over trial).

\section{Included studies}

\section{Study design and setting}

Nine parallel-design randomised controlled trials (RCTs) and one cross-over trial were included in the review. A total of 816 participants were randomised.

- Six were prospective, randomised, double-blind, placebocontrolled trials (metformin versus placebo): Kjotrod 2004; Onalan 2005; Tang 2006; Qublan 2009; Kjotrod 2011; Palomba 2011.

- One was a prospective, open-label, randomised, placebocontrolled, cross-over trial: Fedorcsak 2003. Only data from the pre-cross-over phase of this study were considered for metaanalysis.

- Two were prospective, randomised controlled trials (metformin versus no treatment): Visnova 2003; Doldi 2006.

\section{Participants}

All participants were women undergoing IVF or ICSI treatments. A total of 816 women were randomised: 405 to the placebo and 411 to the metformin groups, respectively.

\section{Baseline characteristics of the studied groups}

Eight studies met the Rotterdam criteria (ESHRE/ASRM 2003) for PCOS: Doldi 2006; Fedorcsak 2003; Kjotrod 2004; Kjotrod 2011; Onalan 2005; Palomba 2011; Qublan 2009; Tang 2006. One study (Visnova 2003) did not meet the Rotterdam criteria because other causes for hyperandrogenism that mimic PCOS (such as congenital adrenal hyperplasia, Cushing's syndrome or androgen-secreting tumours) were not reported as excluded.

Five studies did not report the cause(s) of infertility (Doldi 2006; Fedorcsak 2003; Palomba 2011; Tang 2006; Visnova 2003).

Six studies (Kjotrod 2004; Kjotrod 2011; Onalan 2005; Palomba 2011; Qublan 2009; Tang 2006) provided full baseline characteristics of the participants in both groups (age, BMI, duration of infertility, previously used treatment). Two studies (Fedorcsak 2003; Visnova 2003) provided incomplete baseline characteristics of the study participants (only age and BMI). Doldi 2006 did not report any baseline characteristics of the participants. One study (Doldi 2006) did not report what the exclusion criteria were.

\section{Interventions}

A single study started metformin on the day of ovulation induction with FSH (Visnova 2003); the other eight studies used metformin before and during ovulation induction for IVF or ICSI treatment. Metformin commencement varied from 16 weeks before (earliest) to the first day (latest) of $\mathrm{GnRH}$-agonist administration in the 
studies reporting metformin use before FSH treatment and continued at least until the day of the hCG trigger.

Visnova 2003 used metformin 500 mg twice daily; Qublan 2009 and Tang 2006 used metformin 850 mg twice daily; Doldi 2006, Fedorcsak 2003 and Palomba 2011 used metformin $500 \mathrm{mg}$ three times daily; Onalan 2005 used metformin 850 mg twice daily (BMI $<28 \mathrm{~kg} / \mathrm{m}^{2}$ ) or three times daily (BMI $\left.>=28 \mathrm{~kg} / \mathrm{m}^{2}\right)$; Kjotrod 2004 used metformin $1 \mathrm{~g}$ twice daily. Kjotrod 2011 gradually increased the dose of metformin from $500 \mathrm{gm}$ to $2 \mathrm{~g}$ per day during the first week of treatment.

Eight of the nine studies used long-protocol GnRH-agonist with recombinant FSH (rec-FSH); Doldi 2006 used the short protocol $\mathrm{GnRH}$-antagonist with rec-FSH. Only Visnova 2003 used either recFSH or highly purified FSH (hp-FSH) and only Qublan 2009 used HMG (hp-urinary gonadotrophin).

The method of oocyte fertilisation varied among the trials and included IVF alone (Doldi 2006), ICSI alone (Onalan 2005) or a combination of IVF and ICSI, depending on the cause of infertility (Fedorcsak 2003; Kjotrod 2004; Kjotrod 2011; Qublan 2009; Palomba 2011; Tang 2006). One trial (Visnova 2003) did not report whether IVF or ICSI was performed.

A maximum of two embryos were transferred on day two after oocyte retrieval by Tang 2006 and on day three by Fedorcsak 2003 and Kjotrod 2004. A maximum of three embryos were transferred on day two by Doldi 2006 and on day three by Onalan 2005. Kjotrod 2011 transferred up to two embryos on day two or three. Qublan 2009 transferred two to four embryos on day three. Palomba 2011 transferred a maximum of two embryos on day two, three or five (blastocyst stage). One study (Visnova 2003) did not report on the number of embryos transferred. Two authors (Doldi 2006; Tang 2006) reported performing embryo transfer under ultrasound guidance.

The type of luteal phase support also varied among the trials and included vaginal progesterone capsules (Progestan $200 \mathrm{mg}$ three times daily) (Kjotrod 2004), vaginal progesterone gel (Crinone $90 \mathrm{mg}$ (8\%) daily) (Doldi 2006), vaginal progesterone pessaries (Cyclogest $400 \mathrm{mg}$ daily) (Qublan 2009; Tang 2006) intramuscular progesterone (25 mg daily and $50 \mathrm{mg}$ daily) (Fedorcsak 2003; Palomba 2011), and progesterone, yet the type and dose were selected by the physician (Kjotrod 2011 ). Two studies (Onalan 2005; Visnova 2003) did not report what type of medication was used for luteal phase support.

Onalan 2005 performed selective assisted hatching with laser when: the participant was over 35 years of age; the zona pellucida was considered thick; an abnormally shaped zona was present; or excessive embryo fragmentation or slowly developing embryos were noted. We considered this procedure to be substantially different from the other trials.

\section{Outcomes}

\section{Primary outcomes}

- 5/9 studies reported live birth rate (per woman) (Kjotrod 2004; Kjotrod 2011; Onalan 2005; Palomba 2011; Tang 2006).
- 8/9 studies reported clinical pregnancy rate (Fedorcsak 2003; Kjotrod 2004; Kjotrod 2011; Onalan 2005; Palomba 2011; Qublan 2009; Tang 2006; Visnova 2003).

- 8/9 studies reported OHSS (Doldi 2006; Kjotrod 2004; Kjotrod 2011; Onalan 2005; Palomba 2011; Qublan 2009; Tang 2006; Visnova 2003).

The publication by Onalan 2005 did not provide the live birth rate and we obtained this information after contacting the author by email.

\section{Secondary outcomes}

- 6/9 studies reported miscarriage rate (Fedorcsak 2003; Kjotrod 2004; Kjotrod 2011; Onalan 2005; Palomba 2011; Tang 2006). Miscarriage was defined as the involuntary loss of a pregnancy before 20 weeks gestation.

- 4/9 studies reported participant-reported side effects (Kjotrod 2004; Kjotrod 2011; Onalan 2005; Tang 2006).

- $8 / 9$ studies reported the number of oocytes retrieved, total dose of FSH and the number of days of gonadotrophin treatment per woman (Doldi 2006; Fedorcsak 2003; Kjotrod 2004; Kjotrod 2011; Onalan 2005; Qublan 2009; Tang 2006; Visnova 2003). Only Palomba 2011 did not report these outcomes and we were unsuccessful in contacting the author.

- 6/9 studies reported cancellation rates (Doldi 2006; Kjotrod 2004; Kjotrod 2011; Palomba 2011; Tang 2006; Visnova 2003).

- 5/9 trials reported serum oestradiol level on the day of hCG (Doldi 2006; Kjotrod 2004; Onalan 2005; Qublan 2009; Visnova 2003).

- Only Tang 2006 reported fertilisation rate as the main outcome measure.

\section{Excluded studies}

We excluded 10 studies after full-text reading. Reasons for exclusion are in parentheses:

- Demirol 2006 (not a randomised controlled trial);

- Egbase 2001 (data irregularities);

- Geusa 2002 (data irregularities);

- Kahraman 2001 (control group treated with oral contraceptives and not placebo or no treatment);

- Palomba 2011b (participants were poor responders);

- Schachter 2007 (women specifically undergoing ICSI were not randomised separately);

- Stadtmauer 1999 (participants acted as their own control);

- Stadtmauer 2001 (retrospective data analysis);

- Stadtmauer 2002 (not a randomised controlled trial);

- Tasdemir 2004 (participants undergoing ovulation induction cycles; not IVF or ICSI cycle

\section{Risk of bias in included studies}

See Figure 2 and Figure 3. 
Figure 2. 'Risk of bias' graph: review authors' judgements about each methodological quality item presented as percentages across all included studies.

Random sequence generation (selection bias)

Allocation concealment (selection bias)

Blinding (performance bias and detection bias)

Incomplete outcome data (attrition bias)

Selective reporting (reporting bias)

Other bias
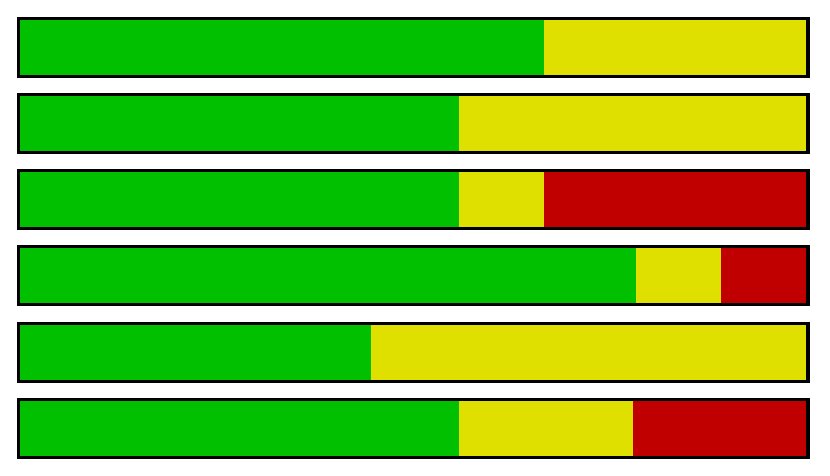

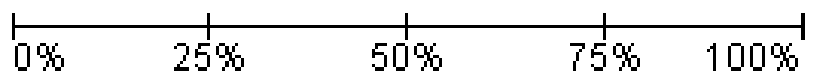


Figure 3. 'Risk of bias' summary: review authors' judgements about each methodological quality item for each included study.

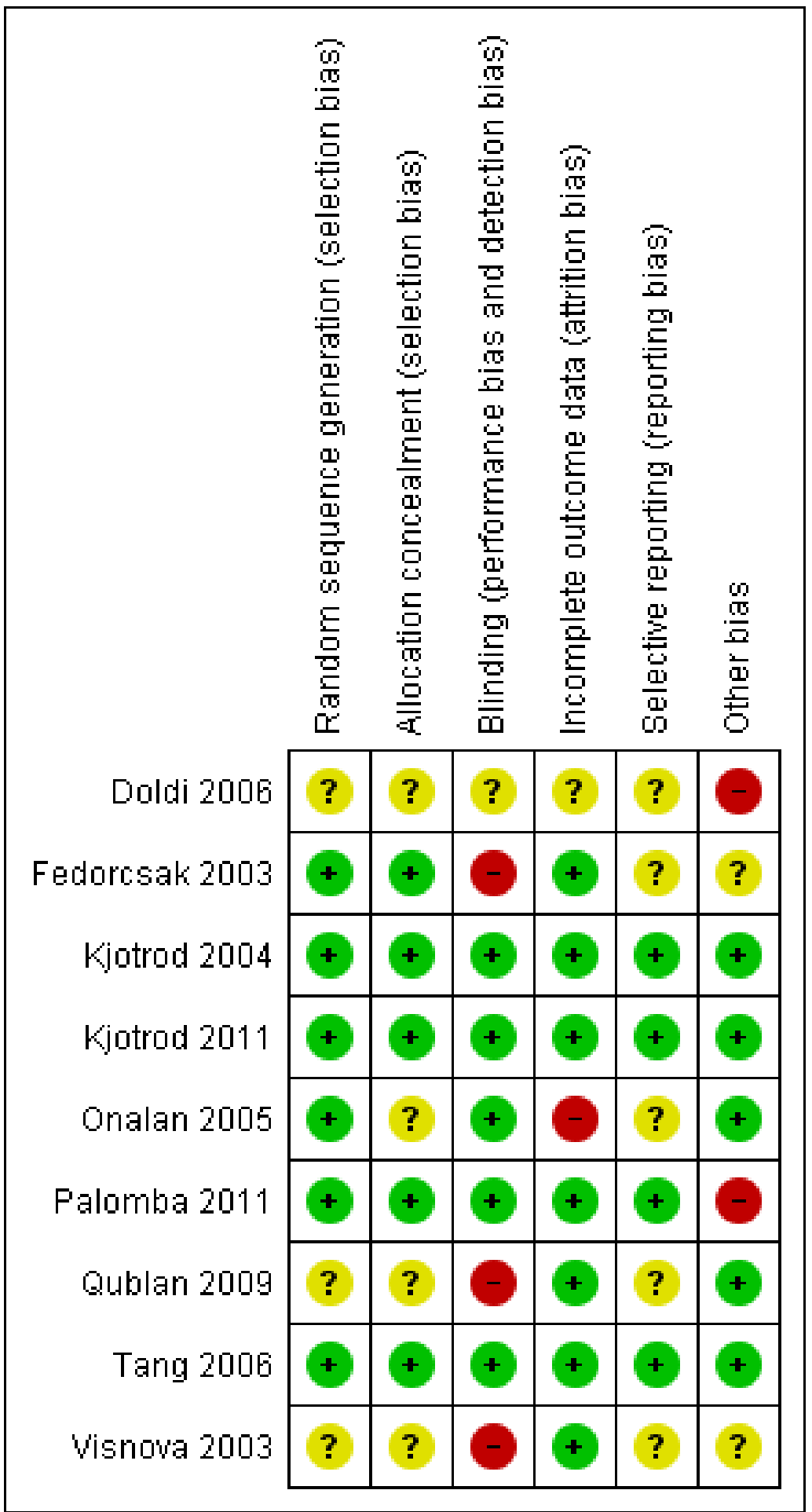

\section{Allocation}

\section{Random sequence generation}

Six trials reported acceptable methods of sequence generation and we classified them as being at low risk of bias for this domain (Fedorcsak 2003; Kjotrod 2004; Kjotrod 2011; Onalan 2005; Palomba
2011; Tang 2006). Four used computer randomisation (Kjotrod 2004; Kjotrod 2011; Onalan 2005; Palomba 2011) and two a random numbers table (Fedorcsak 2003; Tang 2006). The other three studies (Doldi 2006; Qublan 2009; Visnova 2003) did not report what methods were used for sequence generation and we classified them as having an unclear risk of bias for this domain. 


\section{Allocation concealment}

Five studies were at low risk of bias for allocation concealment because they used either sequentially numbered sealed envelopes (Fedorcsak 2003) or codes kept by a third party such as the pharmacy department (Kjotrod 2004; Kjotrod 2011; Palomba 2011) or a trial office (Tang 2006). Four studies (Doldi 2006; Onalan 2005; Qublan 2009; Visnova 2003) did not report the allocation concealment method used and we classified them as having an unclear risk of bias.

\section{Blinding}

We did not consider that blinding was likely to influence findings for the primary review outcomes (live birth rate, clinical pregnancy rate and incidence of OHSS). However for side effects, blinding status could potentially affect findings. Five studies reported doubleblinding (Kjotrod 2004; Kjotrod 2011; Onalan 2005; Palomba 2011; Tang 2006) and we classified them as being at low risk of bias for this domain. Three studies were open-label comparisons (Fedorcsak 2003; Visnova 2003; Doldi 2006) and one was single-blind (Qublan 2009) and therefore we classified it as being at high risk of bias.

\section{Incomplete outcome data}

We judged seven studies (Fedorcsak 2003; Kjotrod 2004; Kjotrod 2011; Palomba 2011; Qublan 2009; Tang 2006; Visnova 2003) to be at low risk of bias because they analysed their data on an intention-totreat basis (trial participants were analysed in the groups to which they were randomised; all participants were included as there were no withdrawals). One study (Doldi 2006) did not report the reasons for withdrawals and we judged it to be at unclear risk of bias for this domain. One study (Onalan 2005) conducted available case analyses (trial participants were analysed in the groups to which they were randomised and only participants who completed the trials were included) and we judged it to be at high risk of bias for this domain.

\section{Selective reporting}

Kjotrod 2004, Kjotrod 2011, Palomba 2011 and Tang 2006 reported live birth and clinical pregnancy rates and OHSS (the primary outcomes of this review); therefore we classified them as being at low risk of bias.
We judged five studies (Doldi 2006; Fedorcsak 2003; Onalan 2005; Qublan 2009; Visnova 2003) to be at unclear risk for selective reporting bias because they failed to report at least one of the following outcomes: live birth, clinical pregnancy or OHSS (the primary outcomes of this review).

\section{Other potential sources of bias}

Doldi 2006 did not report baseline characteristics of the participants nor the causes of infertility and we judged it to be at high risk of bias. We also rated Palomba 2011 as being at high risk of bias in this domain, due to a data discrepancy. We attempted without success to contact the authors to clarify this.

Fedorcsak 2003 and Visnova 2003 did not report the causes of infertility and we thus deemed them to be at unclear risk of bias.

The remaining six studies (Kjotrod 2004; Kjotrod 2011; Onalan 2005; Palomba 2011; Qublan 2009; Tang 2006) reported similar baseline characteristics for participants in both groups and we found no other potential sources of within-study bias. Therefore, we classified these six studies as being at low risk of bias.

\section{Effects of interventions}

See: Summary of findings for the main comparison Metformin treatment before and during IVF or ICSI for women with polycystic ovary syndrome

\section{Comparison of metformin versus placebo or no treatment} Primary outcomes

\subsection{Live birth rate (per woman)}

This was reported by five studies (Kjotrod 2004; Kjotrod 2011; Onalan 2005; Palomba 2011; Tang 2006), all of which utilised long $\mathrm{GnRH}$-agonist stimulation protocol. There was no evidence of a difference in live birth rates between the metformin group and the placebo group (OR 1.39; $95 \% \mathrm{Cl} 0.81$ to 2.40 , five RCTs, 551 women, $\mathrm{I}^{2}=52 \%$, low quality evidence) (Analysis 1.1; Figure 4 ). This suggests that for a woman with a $32 \%$ chance of achieving a live birth using placebo, the corresponding chance using metformin would be between $28 \%$ and $53 \%$. 
Figure 4. Forest plot of comparison: 1 Metformin versus placebo or no treatment, outcome: 1.1 Live birth rate per woman.

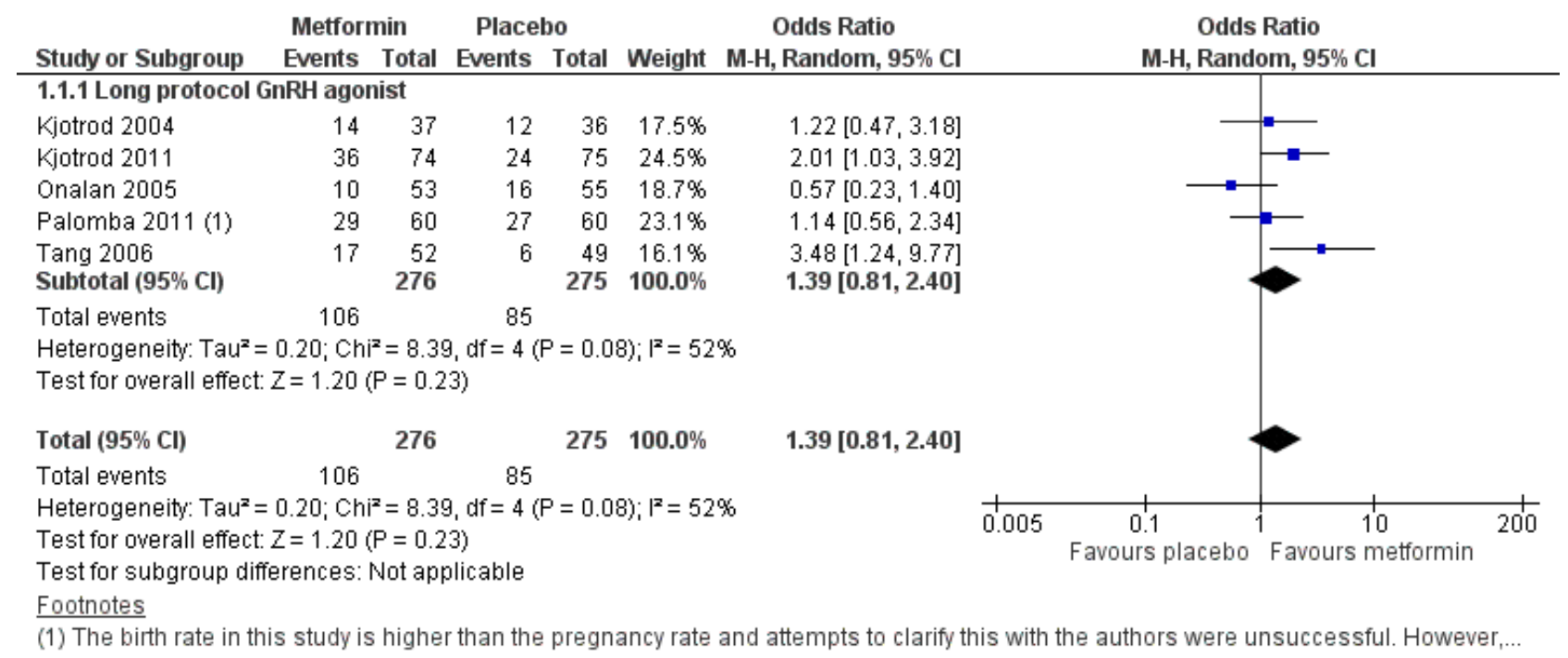

There was substantial statistical heterogeneity in this analysis $(12=$ $52 \%, \mathrm{P}=0.08$ ). Exclusion from analysis of one of the studies (Onalan 2005 ) reduced the 12 statistic to $20 \%$. The only obvious difference between this study and the others was that Onalan 2005 used assisted hatching. As it does not appear biologically plausible that this would account for the difference, we were unable to account for the heterogeneity.

We conducted a post-hoc sensitivity analysis due to a data discrepancy in one of the studies (Palomba 2011). According to the study publication, in both the metformin group and the placebo group the clinical pregnancy rate was lower than the live birth rate (pregnancy 26/60, 24/60; live birth 29/60, 27/60). Attempts to contact the first author have so far received no response. Sensitivity analysis excluding this study yielded an OR of $1.48(95 \% \mathrm{Cl} 0.72$ to 3.02) for live birth, which did not substantially change our findings.

\subsection{Clinical pregnancy rate (per woman)}

Eight studies reported this outcome (Fedorcsak 2003; Kjotrod 2004; Kjotrod 2011; Onalan 2005; Palomba 2011; Qublan 2009; Tang 2006; Visnova 2003), all of which utilised long $\mathrm{GnRH}$-agonist stimulation protocol. Clinical pregnancy rates were higher in the metformin group than in the placebo or no treatment group (OR 1.52; 95\% $\mathrm{Cl} 1.07$ to 2.15 , 8 studies, 775 women, $\mathrm{I}^{2}=18 \%$, moderate quality evidence) (Analysis 1.2; Figure 5). Heterogeneity was low in this analysis $(\mathrm{I}=18 \%, \mathrm{P}=0.28)$. Our findings suggest that for a woman with a $30 \%$ chance of achieving a clinical pregnancy using placebo or no treatment, the corresponding chance using metformin would be between $32 \%$ and $48 \%$. 
Figure 5. Forest plot of comparison: 1 Metformin versus placebo or no treatment, outcome: 1.2 Clinical pregnancy rate per woman.

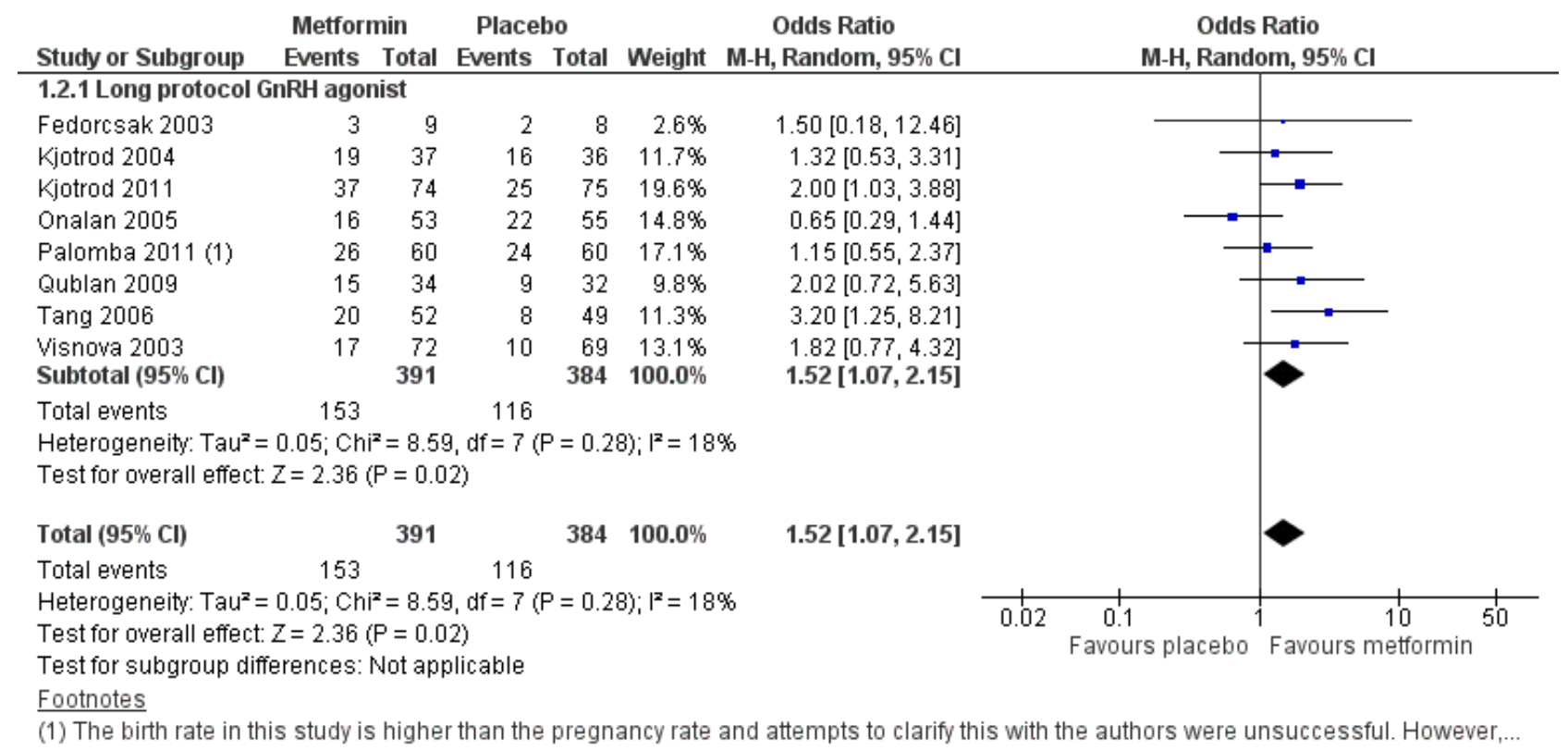

As noted above, we conducted a post-hoc sensitivity analysis due to a data discrepancy in one of the studies (Palomba 2011). Sensitivity analysis excluding this study yielded an OR of $1.61(95 \% \mathrm{Cl} 1.08$ to 2.40 ) for pregnancy, which did not substantially change our findings.

\subsection{Incidence of OHSS}

Eight studies reported this outcome (Doldi 2006; Kjotrod 2004; Kjotrod 2011; Onalan 2005; Palomba 2011; Qublan 2009; Tang 2006;
Visnova 2003). The incidence of OHSS was lower in the metformin group than in the placebo or no treatment group (OR 0.29; $95 \%$ $\mathrm{Cl} 0.18$ to 0.49 , eight RCTs, 798 women, $\mathrm{I} 2=11 \%$, moderate quality evidence) (Analysis 1.3; Figure 6). This suggests that for a woman with a $27 \%$ risk of OHSS without metformin, the corresponding risk using metformin would be between $6 \%$ and $15 \%$. 
Figure 6. Forest plot of comparison: 1 Metformin versus placebo or no treatment, outcome: 1.3 Incidence of OHSS per woman.

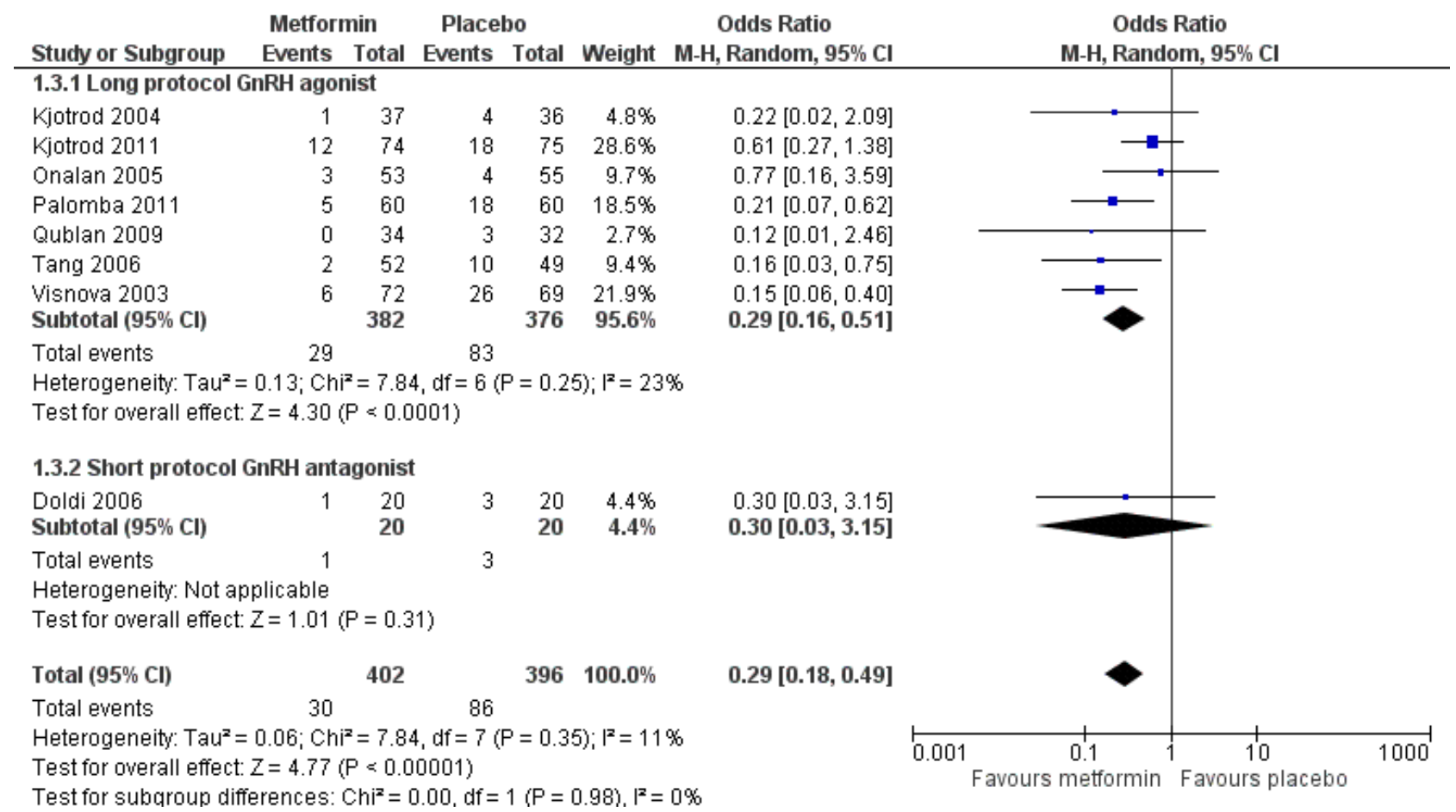

This outcome was also analysed according to two subcategories: studies which used a long protocol with a GnRH-agonist and those using a short protocol with a $\mathrm{GnRH}$-antagonist. The pooled analysis of the seven studies (Kjotrod 2004; Kjotrod 2011; Onalan 2005; Palomba 2011; Qublan 2009; Tang 2006; Visnova 2003) which used the long protocol revealed a benefit from metformin, with lower incidence of OHSS (OR $0.29 ; 95 \% \mathrm{Cl} 0.16$ to $0.51,758$ women, $\mathrm{I}^{2}=$ 23\%). Doldi 2006 used a short-protocol antagonist and found no difference between the two groups (OR 0.30; $95 \% \mathrm{Cl} 0.03$ to 3.15, 40 women).

\section{Secondary outcomes}

\subsection{Miscarriage rate (per woman)}

Six studies were included in this analysis (Fedorcsak 2003; Kjotrod 2004; Kjotrod 2011; Onalan 2005; Palomba 2011; Tang 2006), all of which utilised long $\mathrm{GnRH}$-agonist stimulation protocol. There was no evidence of a difference in miscarriage rates between the groups (OR $0.76 ; 95 \% \mathrm{Cl} 0.43$ to 1.37 , six RCTs, 521 women, $\mathrm{I} 2=0 \%$, moderate quality evidence) Analysis 1.4.

\subsection{Incidence of participant-reported side effects}

Four studies reported this outcome (Kjotrod 2004; Kjotrod 2011; Onalan 2005; Tang 2006), all of which utilised long GnRH-agonist stimulation protocol. Metformin treatment was associated with more side effects $(76 / 216,35.1 \%)$ than placebo (OR $4.49 ; 95 \% \mathrm{Cl}$ 1.88 to 10.72 , four RCTs, 431 women, $\mathrm{l}^{2}=57 \%$ ) (Analysis 1.5 ).

There was substantial heterogeneity for this analysis ( $12=57 \%)$. In three of the four individual trials there were more side effects in the group taking metformin (Kjotrod 2004; Kjotrod 2011; Tang 2006), while the results of Onalan 2005 were considerably different. There were no apparent reasons for the observed heterogeneity among

studies in terms of study methodology or clinical parameters (participants, exposure, outcomes). The doses and duration of metformin treatment used in the four trials were similar.

According to Kjotrod 2004 and Kjotrod 2011, the most frequent side effects associated with metformin were gastrointestinal and included nausea, vomiting, diarrhoea, abdominal discomfort or pain.

\subsection{Number of oocytes retrieved per woman}

Eight studies were included in this analysis (Doldi 2006; Fedorcsak 2003; Kjotrod 2004; Kjotrod 2011; Onalan 2005; Qublan 2009; Tang 2006; Visnova 2003). The mean number of oocytes retrieved per woman did not differ between the two groups (MD -0.76; $95 \% \mathrm{Cl}$ -2.02 to 0.50 , eight RCTs, 635 women, $1^{2}=36 \%$ ) (Analysis 1.6).

These studies were subdivided into two subcategories: those using a long protocol with $\mathrm{GnRH}$-agonist and those using a short protocol with GnRH-antagonist. Only Doldi 2006 used the short-protocol $\mathrm{GnRH}$-antagonist. There was no difference between the results of the two subcategories, and only one individual trial (Qublan 2009) demonstrated a significant difference in the number of oocytes collected between the two treatment groups, with fewer oocytes collected in the metformin group.

\subsection{Total dose of FSH (IU) per woman}

Eight studies were included in this analysis (Doldi 2006; Fedorcsak 2003; Kjotrod 2004; Kjotrod 2011; Onalan 2005; Qublan 2009; Tang 2006; Visnova 2003). The data were not pooled due to extreme heterogeneity $\left(1^{2}=97 \%\right)$. Most of the heterogeneity seemed to be due to Qublan 2009, and exclusion of this study reduced heterogeneity to $1^{2}=54 \%$. However we did not identify any clear 
difference between this study and the others. Six of the eight studies found no evidence of a difference between the two groups.

\subsection{Mean number of days of gonadotrophin treatment}

Eight studies reported this outcome (Doldi 2006; Fedorcsak 2003; Kjotrod 2004; Kjotrod 2011; Onalan 2005; Qublan 2009; Tang 2006; Visnova 2003). The mean number of days of gonadotrophin treatment did not differ significantly between the groups (MD -0.19 days, $95 \% \mathrm{Cl}-0.77$ to 0.40 , eight studies, 643 women, $\mathrm{R}^{2}=56 \%$ ) (Analysis 1.8). There was statistical heterogeneity in this comparison $(12=56 \%)$, which disappeared $(12=0 \%)$ when we excluded Qublan 2009, but we could not identify any clear difference between this study and the others.

This outcome was also analysed by subdividing studies into two subcategories: those using a long protocol with $\mathrm{GnRH}$-agonist and those using a short protocol with $\mathrm{GnRH}$-antagonist. Fedorcsak 2003, Kjotrod 2004, Kjotrod 2011, Onalan 2005, Qublan 2009, Tang 2006 and Visnova 2003 used the long protocol and there were no statistically significant differences between the groups (MD -0.22 days; $95 \% \mathrm{Cl}-0.89$ to 0.45 , seven RCTs, 603 women). Doldi 2006 used the short-protocol $\mathrm{GnRH}$-antagonist and did not find any evidence of a difference between the groups (MD 0.00 days; $95 \% \mathrm{Cl}-1.30$ to $1.30,40$ women).

\subsection{Cycle cancellation rate}

Six studies were included in this analysis (Doldi 2006; Kjotrod 2004; Kjotrod 2011; Palomba 2011; Tang 2006; Visnova 2003). There was no evidence of a difference between the groups in cancellation rates (OR $0.64 ; 95 \% \mathrm{Cl} 0.32$ to 1.29 , six RCTs, 624 women, $\mathrm{I}^{2}=27 \%$ ) (Analysis 1.9).

\subsection{Serum oestradiol level (on the day of hCG): mean level per woman}

Five studies reported this outcome (Doldi 2006; Kjotrod 2004; Onalan 2005; Qublan 2009; Visnova 2003). These studies were not pooled due to very high heterogeneity $(12=91 \%)$ which could not be explained. Three of the five studies reported lower serum oestradiol levels in the metformin group, while the other two studies found no evidence of a difference between the groups.

Tang 2006 reported serum oestradiol levels using multiple linear regression analysis. After adjustment for the total FSH dose and the number of follicles, metformin treatment reduced oestradiol concentration on the day of hCG administration (coefficient $=-35.6$, $\mathrm{P}=0.048)$

\subsection{Serum androgen levels (testosterone, SHBG, free-androgen index)}

Onalan 2005 and Tang 2006 reported serum androgens levels on the day of hCG. It was not possible to pool these data because they were reported as median and range by Onalan 2005 and as geometric measures by Tang 2006 .

Onalan 2005 found no difference in total testosterone between the metformin group (median 3.1, range 2.5 to 3.9 ) and the placebo group (median 3.1, range 2.4 to $3.9, p=0.646$ ) and Tang 2006 reported that while testosterone levels did not change in the metformin group (baseline geometric mean: $2.03 \mathrm{nmol} / \mathrm{l}$, geometric mean on the day of hCG administration: $1.97 \mathrm{nmol} / \mathrm{l}$; $\mathrm{P}=0.892$ ), the placebo group had an increase in testosterone levels (baseline geometric mean: $2.06 \mathrm{nmol} / \mathrm{l}$, geometric mean on the day of hCG administration: $2.52 \mathrm{nmol} / \mathrm{l} ; \mathrm{P}=0.040$ ). In the metformin group, on the day of $\mathrm{hCG}$ administration, there was a decrease in testosterone concentration (geometric mean: 1.96 versus $2.52 \mathrm{nmol} / \mathrm{l} ; \mathrm{P}=0.029$ ) and in the free-androgen index (geometric mean: 2.43 versus 3.34; $\mathrm{P}=0.004)$. See Analysis 1.11 .

\subsection{Fasting insulin and glucose levels}

Onalan 2005 and Tang 2006 reported fasting insulin and glucose levels on the day of hCG. It was not possible to pool their data because they were reported as glucose/insulin ratio (median and range) by Onalan 2005 and as Quantitative Insulin Sensitivity Check Index (QUICKI) by Tang 2006.

Onalan 2005 found no difference in the glucose/insulin ratio between the metformin group (median 6; range 2.4-8.8) and the placebo group (median 6; range 3-10, $p=0.81$ ). Tang 2006 found no difference in the insulin sensitivity test results (QUICKI) between baseline and the day of oocyte retrieval in either group (metformin group - baseline: 0.377 and 0.417 at the day of oocyte retrieval ( $P$ $=0.2$ ) and placebo group - baseline: 0.386 and 0.400 at the day of oocyte retrieval $(P=0.572)$ ). See Analysis 1.12 .

\subsection{Fertilisation rate}

Only Tang 2006 reported fertilisation rate per oocyte retrieved. Metformin did not improve the overall fertilisation rate $(52.9 \%$ versus 54.9\%, $\mathrm{P}=0.641$ ) (Data not shown) (Analysis 1.18).

\section{Other analyses}

Sensitivity analyses for the primary outcomes did not substantially influence any of our findings. There were too few studies to compile a funnel plot in order to assess publication bias.

We conducted a post-hoc sensitivity analysis for our primary outcomes after noting a data discrepancy in one of the studies (Palomba 2011). However, exclusion of this study did not substantially change our findings.

\section{DISCUSSION}

\section{Summary of main results}

We found no conclusive evidence that the co-administration of metformin to women with polycystic ovary syndrome (PCOS) undergoing in vitro fertilisation (IVF) or intracytoplasmic sperm injection (ICSI) treatment increases the live birth rates. However there was evidence that metformin increases clinical pregnancy rates and reduces the rate of OHSS. No difference was found between the groups in miscarriage rates. Adverse events such as gastrointestinal problems were only reported by four studies, but were higher in the metformin group.

Metformin co-treatment appeared to decrease serum oestradiol levels on the day of hCG, but there was no evidence that it had an effect on other ovarian stimulation parameters (total dose of gonadotrophin, number of days of gonadotrophin stimulation, number of oocytes collected and cycle cancellation rate) or embryological outcomes (fertilisation rate).

Metformin reduced the risk of ovarian hyperstimulation syndrome (OHSS) by approximately $63 \%$ but increased the risk of side effects three-fold. Although the reason why metformin reduces the risk of OHSS is not clear, it has been hypothesised that since it decreases hyperinsulinaemia, it could also reduce the production of vascular 
endothelial growth factor (VEGF), one of the most important factors involved in the pathophysiology of the syndrome. In addition, metformin is associated with a statistically significant effect on oestradiol levels, an important risk factor for OHSS.

\section{Overall completeness and applicability of evidence}

The increased number of studies included in this updated version of the review has improved the statistical power of our metaanalyses. Five of the nine trials performed a priori sample size calculations to assess their primary outcome measures. A total of 816 participants under 40 years of age were included. Eight of the nine included studies met the Rotterdam consensus criteria (ESHRE/ASRM 2003) for the diagnosis of PCOS and excluded other causes of hyperandrogenism. The only study that did not meet the Rotterdam consensus criteria may have included women with other causes for hyperandrogenism that mimic PCOS (such as congenital adrenal hyperplasia, Cushing's syndrome and androgen-secreting tumours). None of the nine trials reported previous ovarian surgery in their baseline characteristics and three trials did not report the cause of infertility.

Eight of the nine trials included in this review provided data on clinical pregnancy. However, only four trials reported live birth and none reported the rate of healthy take-home baby, which is considered the most important long-term outcome of interest to consumers.The primary endpoints of the five trials were either not clearly reported or were related to ovarian response parameters.

\section{Quality of the evidence}

See Summary of findings table 1 . The table was developed in GRADEpro 2011. The overall quality of the evidence was moderate for the outcomes of clinical pregnancy, OHSS and miscarriage, and low for other outcomes. The main limitations in the evidence were imprecision and inconsistency. We conducted a post-hoc sensitivity analysis for our primary outcomes after noting a data discrepancy in one of the studies. However, exclusion of this study did not substantially change our findings

Four of the nine included studies were at low risk of bias in all domains. Limitation in the other studies included failure to report details of study methods and lack of blinding. See Figure 2 and Figure 3 for the 'Risk of bias' graph and summary. Heterogeneity was moderate or low for clinical outcomes. Data for two of the laboratory outcomes (FSH dose and serum oestradiol level) were not pooled due to very high levels of unexplained heterogeneity.

\section{Potential biases in the review process}

A limitation of this review is the lack of full data from some studies, despite our attempts to obtain missing information from study authors. Whenever possible, we performed analyses based on intention-to-treat, to minimise bias. Additionally, since the number of included studies was small, it was not possible to assess the risk of publication bias.

We conducted a through search and are confident that we have included in the review all existing randomised trials which have assessed the use of metformin in PCOS women undergoing ART cycles and which reported clinically relevant outcomes (live birth rate, clinical pregnancy rate and incidence of OHSS).

\section{Agreements and disagreements with other studies or reviews}

The results of this updated review are in agreement with other reviews (Costello 2006; Tang 2012).

\section{AUTHORS' CONCLUSIONS}

\section{Implications for practice}

This review found no conclusive evidence that metformin treatment before or during ART cycles improves live birth rates in women with PCOS. However, the use of this insulin-sensitising agent increased clinical pregnancy rates and decreased the risk of OHSS.

\section{Implications for research}

Further large, well-designed and well-executed randomised controlled trials are necessary to answer definitively the question of whether the use of metformin in women with polycystic ovary syndrome and undergoing assisted reproductive technology improves the live birth rate. All studies should report OHSS and other adverse events.

\section{ACKNOWLEDGEMENTS}

The review authors wish to express their gratitude to the Brazilian Cochrane Centre and the Menstrual Disorders and Subfertility Group, especially to Ms Helen Nagels and to Marian Showell, for their thoughtful comments and suggestions and for their continued support in developing and updating this systematic review. 


\section{R E F E R E N C E S}

\section{References to studies included in this review}

Doldi 2006 \{published and unpublished data\}

* Doldi N, Persico P, Di Sebastiano F, Marsiglio E, Ferrari A. Gonadotropin-releasing hormone antagonist and metformin for treatment of polycystic ovary syndrome patients undergoing in vitro fertilization-embryo transfer. Gynecological Endocrinology 2006;22(5):235-8.

\section{Fedorcsak 2003 \{published data only\}}

* Fedorcsak P, Dale PO, Storeng R, Abyholm T, Tanbo T. The effect of metformin on ovarian stimulation and in vitro fertilization in insulin-resistant women with polycystic ovary syndrome: an open-label randomized cross-over trial. Gynecological Endocrinology 2003;17:207-14.

\section{Kjotrod 2004 \{published data only\}}

Kjotrod S, von Düring V, Sunde A, Carlsen SM. Metformin treatment before IVF/ICSI in polycystic ovary syndrome women: a prospective, randomized, double-blind study. Human Reproduction 2003;18 Suppl 1:42-3.

* Kjotrod SB, von Düring V, Carlsen SM. Metformin treatment before IVF/ICSI in women with polycystic ovary syndrome; a prospective, randomized, double blind study. Human Reproduction 2004;19(6):1315-22.

Kjøtrød SB, Romundstad P, von Düring V, Sunde A, Carlsen SM. Prospective, randomized trial of metformin and vitamins for the reduction of plasma homocysteine in insulinresistant polycystic ovary syndrome. Fertility and Sterility 2008;89(3):635-41.

\section{Kjotrod 2011 \{published data only\}}

Kjotrod S, Carlsen SM, Rasmussen PE, Holst-Larsen T, Mellembakken J, Thurin-Kjellberg A, et al. Metformin treatment before and during IVF or ICSI in PCOS women with BMI $<28 \mathrm{~kg} /$ m2. Human Reproduction 2010;25(Suppl 1):i286-7.

* Kjotrod SB, Carlsen SM, Rasmussen PE, Holst-Larsen T, Mellembakken J, Thurin-Kjellberg A, et al. Use of metformin before and during assisted reproductive technology in nonobese young infertile women with polycystic ovary syndrome: a prospective, randomized, double-blind, multi-centre study. Human Reproduction 2011;26(8):2045-53. [PUBMED: 21606131]

Onalan 2005 \{published data only\}

* Onalan G, Pabuccu R, Goktolga U, Ceyhan T, Bagis T, Cincik M. Metformin treatment in patients with polycystic ovary syndrome undergoing in vitro fertilization: a prospective randomized trial. Fertility and Sterility 2005;84(3):798-801.

\section{Palomba 2011 \{published data only\}}

* Palomba S, Falbo A, Carrillo L, Villani MT, Orio F, Russo T, et al. Metformin reduces risk of ovarian hyperstimulation syndrome in patients with polycystic ovary syndrome during gonadotropin-stimulated in vitro fertilization cycles: a randomized, controlled trial. Fertility and Sterility 2011;96:1384-90.
Qublan 2009 \{published data only\}

Qublan HS, Al-Khaderei S, Abu-Salem AN, Al-Zpoon A, AlKhateeb M, Al-Ibrahim N, et al. Metformin in the treatment of clomiphene citrate-resistant women with polycystic ovary syndrome undergoing in vitro fertilisation treatment: a randomised controlled trial. Journal of Obstetrics and Gynecology 2009;29(7):651-5.

Tang 2006 \{published data only\}

* Tang T, Glanville J, Orsi N, Barth JH, Balen AH. The use of metformin for women with PCOS undergoing IVF treatment. Human Reproduction 2006;21(6):1416-25.

\section{Visnova 2003 \{published data only\}}

* Visnova H, Ventruba P, Crha I, Zakova J. Importance of sensitization of insulin receptors in the prevention of ovarian hyperstimulation syndrome [Význam senzitizace inzulinových receptoru pro prevenci ovariálního hyperstimulacního syndromu]. Ceská Gynekologie 2003;68(3):155-62.

Visnova H, Ventruba P, Crha I, Zakova J. The impact of insulin receptor sensitization on prevention of ovarian hyperstimulation syndrome. Human Reproduction 2002;17 Suppl:180.

\section{References to studies excluded from this review}

Demirol 2006 \{published data only\}

Demirol A, Sari T, Girgin B, Kent E, Gurgan T. The effect of metformin treatment on the ICSI cycle outcome in PCOS patients. Human Reproduction 2006;21(Suppl 1):i88.

Egbase 2001 \{published data only\}

* Egbase PE, Al Sharhan M, Buzaber M, Grudzinskas JG. Prospective randomised study of metformin in IVF and embryo transfer treatment cycles in obese patients with polycystic ovarian syndrome. Human Reproduction 2001;16 Suppl 1:202.

Geusa 2002 \{published data only\}

* Geusa S, Stanziano A, Causio F, Pansini N, Sarcina E. The efficacy of insulin-sensitizing agent (metformin) in PCOS and insulin resistance patients undergoing IVF treatment. Human Reproduction 2002;17 Suppl:115.

Kahraman 2001 \{published data only\}

* Kahraman S, Vanlioglu F, Yakin K, Cengiz S, Karlikaya G. A comparative trial of metformin and oral contraceptive pretreatment in patients with polycystic ovary syndrome undergoing ICSI for severe male factor infertility. Fertility and Sterility 2001;76 Suppl 1(3):67.

Palomba 2011b \{published data only\}

Palomba S, Falbo A, Di Cello A, Cappiello F, Tolino A, Zullo F. Does metformin affect the ovarian response to gonadotropins for in vitro fertilization treatment in patients with polycystic ovary syndrome and reduced ovarian reserve? A randomized controlled trial. Fertility and Sterility 2011;96(5):1128-33. [PUBMED: 21917254] 
Schachter 2007 \{published data only\}

* Schachter M, Raziel A, Strassburger D, Rotem C, Ron-El R, Friedler S. Prospective, randomized trial of metformin and vitamins for the reduction of plasma homocysteine in insulinresistant polycystic ovary syndrome. Fertility and Sterility 2007;88(1):227-30.

\section{Stadtmauer 1999 \{published data only\}}

Stadtmauer L, Riehl R, Toma S, Talbert L. Use of metformin in patients with PCOS undergoing IVF-ET improves outcomes. International Journal of Gynecology and Obstetrics 2000;70:p.B41.

* Stadtmauer LA, Riehl RM, Toma SK, Huang S, Barker S, Talbert LM. Metformin treatment of patients with polycystic ovarian syndrome undergoing IVF increases the number of mature oocytes, the fertilization rate and the number of embryos with changes in the levels of insulin-like growth factor. Fertility and Sterility 1999;72 Suppl 1(3):12.

\section{Stadtmauer 2001 \{published data only\}}

* Stadtmauer LA, Toma SK, Riehl RM, Talbert LM. Metformin treatment of patients with polycystic ovary syndrome undergoing in vitro fertilization improves outcomes and is associated with modulation of the insulin-like growth factors. Fertility and Sterility 2001;75(3):505-9.

\section{Stadtmauer 2002 \{published data only\}}

* Stadtmauer LA, Wong BC, Oehninger S. Impact of metformin therapy on ovarian stimulation and outcome in 'coasted' patients with polycystic ovary syndrome undergoing in-vitro fertilization. Reproductive Biomedicine Online 2002;5(2):112-6.

\section{Tasdemir 2004 \{published data only\}}

Tasdemir S, Ficicioglu C, Yalti S, Gurbuz B, Basaran T, Yildirim G. The effect of metformin treatment to ovarian response in cases with PCOS. Archives of Gynecology and Obstetrics 2004;269(2):121-4. [PUBMED: 12764624]

\section{References to studies awaiting assessment}

Tang 2010 \{published data only\}

* Tang T, Barth JH, Balen AH. Effect of metformin on follicular anti-Mullerian hormone concentrations in women with PCOS undergoing IVF treatment. Human Reproduction 2010;25(Suppl 1):i68.

\section{Additional references}

\section{Aboulghar 2003}

Aboulghar MA, Mansour RT. Ovarian hyperstimulation syndrome: classifications and critical analysis of preventive measures. Human Reproduction Update 2003;9:275-89.

\section{Adashi 1985}

Adashi EY, Resnick CE, D'Ercole AJ, Svoboda ME, Van Wyk JJ. Insulin-like growth factors as intraovarian regulators of granulosa cell growth and function. Endocrine Review 1985;6:400-20.

\section{Attia 2001}

Attia GR, Rainey WE, Carr BR. Metformin directly inhibits androgen production in human thecal cells. Fertility and Sterility 2001;76:517-24.

\section{Balen 2004}

Balen A. The pathophysiology of polycystic ovary syndrome: trying to understand PCOS and its endocrinology. Best Practice \& Research. Clinical Obstetrics \& Gynaecology 2004;18:685-6.

\section{Barbieri 1986}

Barbieri RL, Makris A, Randall RW, Daniels G, Kistner RW, Ryan KJ. Insulin stimulates androgen accumulation in incubations of ovarian stroma obtained from women with hyperandrogenism. Journal of Clinical Endocrinology and Metabolism 1986;62:904-10.

\section{Barbieri 2000}

Barbieri RL. Induction of ovulation in infertile women with hyperandrogenism and insulin resistance. American Journal of Obstetrics and Gynecology 2000;183:1412-8.

\section{Costello 2006}

Costello MF, Chapman M, Conway U. A systematic review and meta-analysis of randomized controlled trials on metformin co-administration during gonadotrophin ovulation induction or IVF in women with polycystic ovary syndrome. Human Reproduction 2006;21:1387-99.

\section{Costello 2007}

Costello M, Shrestha B, Eden J, Sjoblom P, Johnson N. Insulinsensitising drugs versus the combined oral contraceptive pill for hirsutism, acne and risk of diabetes, cardiovascular disease, and endometrial cancer in polycystic ovary syndrome. Cochrane Database of Systematic Reviews 2007, Issue 1. [DOI: 10.1002/14651858.CD005552.pub2]

\section{Dunaif 1989}

Dunaif A, Segal KR, Futterweit W, Dobrjansky A. Profound peripheral insulin resistance, independent of obesity, in polycystic ovary syndrome. Diabetes 1989;38:1165-74.

\section{Dunn 1995}

Dunn CJ, Peters DH. Metformin. A review of its pharmacological properties and therapeutic use in non-insulin-dependent diabetes mellitus. Drugs 1995;49:721-49.

\section{ESHRE/ASRM 2003}

Rotterdam ESHRE/ASRM - Sponsored PCOS Consensus Workshop Group. Revised 2003 consensus on diagnostic criteria and long-term health risks related to polycystic ovary syndrome. Fertility and Sterility 2004;81:19-25.

\section{Frank 1995}

Frank S. Polycystic ovary syndrome. New England Journal of Medicine 1995;333:853-61.

\section{GRADEpro 2011 [Computer program]}

GRADE Working Group. GRADE Profiler. Version Version 3.2 for Windows. Brozek J, Oxman A, Schünemann H, 2011. 


\section{Higgins 2011}

Higgins JPT, Green S (editors). Cochrane Handbook for Systematic Reviews of Interventions Version 5.1.0 [updated March 2011]. The Cochrane Collaboration, 2011. Available from www.cochrane-handbook.org.

\section{Jungheim 2010}

Jungheim ES, Odibo AO. Fertility treatment in women with polycystic ovary syndrome: a decision analysis of different oral ovulation induction agents. Fertility and Sterility 2010;94(7):2659-64.

\section{Knochenhauer 1998}

Knochenhauer ES, Key TJ, Kahsar-Miller M, Waggoner W, Boots LR, Azziz R. Prevalence of the polycystic ovary syndrome in unselected black and white women of the southeastern United States: a prospective study. Journal of Clinical Endocrinology and Metabolism 1998;83:3078-82.

\section{Kocak 2002}

Kocak M, Caliskan E, Simsir C, Haberal A. Metformin therapy improves ovulatory rates, cervical scores and pregnancy rates in clomiphene citrate-resistant women with polycystic ovary syndrome. Fertility and Sterility 2002;77:101-6.

\section{Nardo 2001}

Nardo LG, Rai R. Metformin therapy in the management of polycystic ovary syndrome: endocrine, metabolic and reproductive effects. Gynecology and Endocrinology 2001;15:373-80

\section{Nestler 1991}

Nestler JE, Powers LP, Matt DW, Steingold KA, Plymate SR, Rittmaster RS, et al. A direct effect of hyperinsulinemia on serum sex hormone-binding globulin levels in obese women with the polycystic ovary syndrome. Journal of Clinical Endocrinology and Metabolism 1991;72:83-9.

\section{Nestler 2002}

Nestler JE, Stovall D, Akhter N, luorno MJ, Jakubowicz DJ. Strategies for the use of insulin-sensitizing drugs to treat infertility in women with polycystic ovary syndrome. Fertility and Sterility 2002;77:209-15.

\section{CHARACTERISTICS OF STUDIES}

Characteristics of included studies [ordered by study ID]

\section{Palomba 2010}

Palomba S, Falbo A, Russo T, Orio F, Tolino A, Zullo F. Systemic and local effects of metformin administration in patients with polycystic ovary syndrome (PCOS): relationship to the ovulatory response. Human Reproduction 2010;25(4):1005-13.

\section{RevMan 2011 [Computer program]}

The Nordic Cochrane Centre, The Cochrane Collaboration. Review Manager (RevMan). Version 5.1. Copenhagen: The Nordic Cochrane Centre, The Cochrane Collaboration, 2011.

\section{Speroff 1995}

Speroff L, Glass RH, Kase NG. Anovulation and polycystic ovary [Anovulação e o Ovário Policístico]. Clinical Gynecology, Endocrinology and Infertility. 5th Edition. São Paulo: Manole, 1995:477-502.

\section{Tang 2012}

Tang T, Lord JM, Norman RJ, Yasmin E, Balen AH. Insulinsensitising drugs (metformin, rosiglitazone, pioglitazone, Dchiro-inositol) for women with polycystic ovary syndrome, oligo amenorrhoea and subfertility. Cochrane Database of Systematic Reviews 2012, Issue 5. [DOI: 10.1002/14651858.CD003053.pub5]

\section{Thessaloniki ESHRE/ASRM-Sponsored PCOS 2008}

Thessaloniki ESHRE/ASRM-Sponsored PCOS Consensus Workshop Group. Consensus on infertility treatment related to polycystic ovary syndrome. Fertility and Sterility 2008;89(3):505-22.

\section{Tsilchorozidou 2004}

Tsilchorozidou T, Overton C, Conway GS. The pathophysiology of polycystic ovary syndrome. Clinical Endocrinology 2004;60(1):1-17.

\section{Yarali 2004}

Yarali H, Zeyneloglu HB. Gonadotrophin treatment in patients with polycystic ovary syndrome. Reproductive Biomedicine Online 2004;8:528-37.

* Indicates the major publication for the study

Doldi 2006

Methods

Generation of the allocation sequence: not reported

Allocation concealment method: not reported

Blinding method: not reported

Number and reasons for withdrawals: not reported

ITT analysis: yes

The authors did not provide additional information about allocation concealment and generation of allocation sequence methods 
Doldi 2006 (Continued)

Prospective randomised trial

Metformin versus no treatment

Participants PCOS participants were randomised (20 in the metformin group and 20 in the placebo group)
Diagnosis of PCOS followed the Rotterdam criteria (ESHRE/ASRM)
Exclusion criteria:
a) congenital adrenal hyperplasia
b) Cushing's syndrome
c) androgen-producing tumours
d) hyperprolactinaemia
e) thyroid dysfunction
f) participant age older than 40 years
g) FSH > 12 mIU/ml
The causes of infertility were not reported
Participants did not take any ovulation drugs or hormones for at least 3 months prior to the trial

Interventions Group A was pretreated for 2 months with metformin $1.5 \mathrm{~g} / \mathrm{day}$ until the embryo transfer day

Protocol for controlled ovarian hyperstimulation: short-protocol GnRH-antagonist (cetrorelix acetate, Cetrotide ${ }^{\circledR}$ ) with step up rec-FSH (Gonal $\mathrm{F}^{\circledR}$ - starting dose $150 \mathrm{IU}$ ). GnRH-antagonist, cetrorelix acetate $0.25 \mathrm{mg} /$ day, was started when the leading follicle reached $14 \mathrm{~mm}$ diameter on ultrasound scan and stopped on the day of hCG

Recombinant hCG (Ovitrelle ${ }^{\circledR} 250$ micrograms) was given when 2 or 3 follicles reached $16 \mathrm{~mm}$ in diameter on ultrasound scan. Oocyte retrieval was performed within 36 hrs of hCG injection. No more than 3 oocyte were fertilised (in accordance with Italian law)

Assisted reproductive technology (ART): IVF

Embryo transfer: maximum of 3 embryos were transferred per participant on day 2 after oocyte retrieval under abdominal US guidance

Catheter used for transfer: not reported

Luteal phase support: progesterone $90 \mathrm{mg}\left(\right.$ Crinone $\left.8^{\circledR}\right)$ was given on the day of oocyte retrieval and was continued until menstruation or a positive pregnancy test

\begin{tabular}{|c|c|c|}
\hline Outcomes & \multicolumn{2}{|c|}{$\begin{array}{l}\text { a) Number of ampoules of rec-FSH } \\
\text { b) Oestradiol levels } \\
\text { c) Cancelled cycles } \\
\text { d) Incidence of OHSS } \\
\text { e) Number of mature oocytes }\end{array}$} \\
\hline Notes & \multicolumn{2}{|c|}{ Country of the study: Italy } \\
\hline \multicolumn{3}{|l|}{ Risk of bias } \\
\hline Bias & Authors' judgement & Support for judgement \\
\hline $\begin{array}{l}\text { Random sequence genera- } \\
\text { tion (selection bias) }\end{array}$ & Unclear risk & Not stated \\
\hline $\begin{array}{l}\text { Allocation concealment } \\
\text { (selection bias) }\end{array}$ & Unclear risk & Not stated \\
\hline $\begin{array}{l}\text { Blinding (performance } \\
\text { bias and detection bias) } \\
\text { All outcomes }\end{array}$ & Unclear risk & Not stated \\
\hline $\begin{array}{l}\text { Incomplete outcome data } \\
\text { (attrition bias) } \\
\text { All outcomes }\end{array}$ & Unclear risk & Reasons for withdrawals were not reported \\
\hline
\end{tabular}


Doldi 2006 (Continued)

Selective reporting (re- Unclear risk Live birth and clinical pregnancy rates were not assessed porting bias)

Other bias

High risk

No power calculation. Neither the causes of infertility nor the baseline characteristics of the 2 groups were reported

Fedorcsak 2003

Methods

Generation of the allocation sequence: table of random numbers

Allocation concealment method: sealed, opaque envelopes serially numbered

Blinding method: does not apply (open-label cross-over trial)

Number and reasons for withdrawals: not reported

ITT analysis: yes

Prospective, open-label, randomised cross-over trial. Only data from the pre-cross-over phase of this study were considered for meta-analysis

Women were randomised to receive 2 consecutive cycles: metformin versus no treatment (control) - no treatment versus metformin

Participants

17 PCOS participants were randomised ( 9 in the metformin group and 8 in the placebo group) Diagnosis of PCOS followed the Rotterdam criteria (ESHRE/ASRM). All participants had insulin-resistance, based on an insulin resistance index

Exclusion criteria:

a) congenital adrenal hyperplasia

b) Cushing's syndrome

c) androgen-producing tumours

d) hyperprolactinaemia

Age: 23 to 35 years (median 31)

The causes of infertility were not reported

Only the first arm was compared: 8 participants in the no treatment group versus 9 participants in the metformin group

Interventions

Metformin $500 \mathrm{mg}$ tid was started 3 weeks before down-regulation with $\mathrm{GnRH}$-agonist began and continued until the day of hCG injection

Protocol for controlled ovarian hyperstimulation: long luteal phase pituitary down-regulation using the $\mathrm{GnRH}$ analogue buserelin acetate $600 \mu \mathrm{g}$ (Suprefact ${ }^{\circledR}$ ) with step-up rec-FSH (Gonal $\mathrm{F}^{\circledR}$ - starting dose $150 \mathrm{IU}$ ). hCG (Profasi ${ }^{\circledR} 10000 \mathrm{IU}$ ) was administered when at least 2 follicles were larger than 18 $\mathrm{mm}$. Oocyte retrieval was performed within 34 to $38 \mathrm{hrs}$ of hCG injection

Assisted reproductive technology (ART): IVF or ICSI

Embryo transfer: maximum of 2 embryos were transferred per participant on day 3 after oocyte retrieval

Catheter used for transfer: not reported

Luteal phase support: intramuscular progesterone $(25 \mathrm{mg} /$ day $)$ until day 14 after follicle puncture

\section{Outcomes Primary outcomes:}

a) total dose of FSH given during stimulation

b) number of collected oocytes

\section{Secondary outcomes:}

a) number of days of gonadotrophin

b) fertilisation rate

c) number of embryos transferred

d) pregnancy rate per woman

e) miscarriage rate 
Fedorcsak 2003 (Continued)

f) incidence of OHSS

d) incidence of adverse side effects

\begin{tabular}{|c|c|c|}
\hline Notes & Country of the study: & orway \\
\hline \multicolumn{3}{|l|}{ Risk of bias } \\
\hline Bias & Authors' judgement & Support for judgement \\
\hline $\begin{array}{l}\text { Random sequence genera- } \\
\text { tion (selection bias) }\end{array}$ & Low risk & Adequate - random numbers table \\
\hline $\begin{array}{l}\text { Allocation concealment } \\
\text { (selection bias) }\end{array}$ & Low risk & Adequate - sealed, opaque envelopes serially numbered \\
\hline $\begin{array}{l}\text { Blinding (performance } \\
\text { bias and detection bias) } \\
\text { All outcomes }\end{array}$ & High risk & Open-label cross-over trial \\
\hline $\begin{array}{l}\text { Incomplete outcome data } \\
\text { (attrition bias) } \\
\text { All outcomes }\end{array}$ & Low risk & There were no withdrawals in the phase analysed (pre-cross-over phase) \\
\hline $\begin{array}{l}\text { Selective reporting (re- } \\
\text { porting bias) }\end{array}$ & Unclear risk & Live birth rate was not evaluated \\
\hline Other bias & Unclear risk & No power calculation. The causes of infertility were not reported \\
\hline
\end{tabular}

Kjotrod 2004

Generation of the allocation sequence: computer randomisation system
Allocation concealment method: codes were kept by a third party in the pharmacy department
Blinding method: yes
Number and reasons for withdrawals: reported
ITT analysis: yes
Prospective, randomised, double-blind, placebo-controlled trial
Metformin versus placebo
73 PCOS participants were randomised (37 in the metformin group and 36 in the placebo group)
Diagnosis of PCOS followed the Rotterdam criteria (ESHRE/ASRM)
4 participants withdrew for personal reasons
4 women in the metformin group and 2 in the placebo group became pregnant spontaneously
63 participants started ovulation induction (31 participants in the metformin group and 32 in the place-
bo group)
2 women were excluded before oocyte retrieval (1 poor responder and 1 OHSS)
4 participants dropped out before embryo transfer ( 2 due to OHSS and 2 due to lack of good quality
embryos)
57 participants received embryos
ITT analysis was performed for primary outcomes
Infertility factors were reported
Both groups were matched for age, cause and duration of infertility, BMI and gravity
Exclusion criteria:


Kjotrod 2004 (Continued)
a) diabetes mellitus
b) renal insufficiency
c) liver disease
d) treatment with oral glucocorticoids
e) congenital adrenal hyperplasia
g) androgen-producing tumours
h) hyperprolactinaemia
f) thyroid dysfunction

Interventions

Metformin $500 \mathrm{mg}$ bid (gradually increasing the dose during the first 2 weeks) for at least 16 weeks until the day of hCG injection

Protocol for controlled ovarian hyperstimulation: long luteal phase pituitary down-regulation using the $\mathrm{GnRH}$ analogue nafarelin $800 \mu \mathrm{g}$ daily (Synarela ${ }^{\circledR}$ ) with rec-FSH (Puregon ${ }^{\circledR} 100 \mathrm{IU}$ daily in normal weight women or $150 \mathrm{IU}$ in obese women). Oocyte retrieval was performed within 34 to $36 \mathrm{hrs}$ after hCG injection (Pregnyl ${ }^{\circledR} 5000$ IU)

Assisted reproductive technology (ART): IVF or ICSI

Embryo transfer: maximum of 2 embryos were transferred per participant on day 3 after oocyte retrieval

Catheter used for transfer: not reported

Luteal phase support: vaginal progesterone (Progestan $\left.{ }^{\circledR}\right)$ for 2 weeks $(200 \mathrm{mg}$ tid)

Primary outcomes:
a) number of days of gonadotrophins
b) serum E2 levels on the day of hCG
Secondary outcomes:
a) total dose of FSH given during stimulation
b) number of collected oocytes
c) fertilisation rate
d) number of good quality embryos
e) pregnancy rate per woman
f) clinical pregnancy rate per woman
g) live birth rate per woman
h) incidence of OHSS

Notes Country of the study: Norway

\section{Risk of bias}

\begin{tabular}{lll}
\hline Bias & Authors' judgement & Support for judgement \\
\hline $\begin{array}{l}\text { Random sequence genera- } \\
\text { tion (selection bias) }\end{array}$ & Low risk & Adequate - computer randomisation system \\
\hline $\begin{array}{l}\text { Allocation concealment } \\
\text { (selection bias) }\end{array}$ & Low risk & Adequate - codes kept by a third party in the pharmacy department \\
\hline $\begin{array}{l}\text { Blinding (performance } \\
\text { bias and detection bias) } \\
\begin{array}{l}\text { All outcomes } \\
\hline\end{array}\end{array}$ & Low risk & Double-blinded \\
\hline
\end{tabular}

\begin{tabular}{lll}
$\begin{array}{l}\text { Incomplete outcome data } \\
\text { (attrition bias) } \\
\text { All outcomes }\end{array}$ & Low risk & Number and reasons for withdrawals were reported \\
\hline $\begin{array}{l}\text { Selective reporting (re- } \\
\text { porting bias) }\end{array}$ & Low risk & All main outcomes were reported \\
\hline
\end{tabular}


Kjotrod 2004 (Continued)

$\begin{array}{ll}\text { Other bias } \quad \text { Low risk } & \begin{array}{l}\text { Power calculation was performed. There were no significant differences in the } \\ \text { baseline characteristics of the participants between the } 2 \text { groups }\end{array}\end{array}$

Kjotrod 2011

\begin{tabular}{|c|c|}
\hline \multirow[t]{6}{*}{ Methods } & Generation of the allocation sequence: computer randomisation system \\
\hline & Allocation concealment method: codes were kept by a third party in the pharmacy department \\
\hline & Blinding method: yes \\
\hline & Number and reasons for withdrawals: reported \\
\hline & ITT analysis: yes \\
\hline & $\begin{array}{l}\text { Multi-centre, prospective, randomised, double-blind, placebo-controlled trial } \\
\text { Metformin versus placebo }\end{array}$ \\
\hline \multirow[t]{19}{*}{ Participants } & $\begin{array}{l}150 \text { PCOS participants were randomised ( } 74 \text { in the metformin group and } 76 \text { in the placebo group); how- } \\
\text { ever } 1 \text { participant in the placebo group withdrew her consent just after randomisation }\end{array}$ \\
\hline & $\begin{array}{l}\text { The ITT population in the study consisted of } 149 \text { women ( } 74 \text { in the metformin group, } 75 \text { in the placebo } \\
\text { group) }\end{array}$ \\
\hline & Diagnosis of PCOS followed the Rotterdam criteria (ESHRE/ASRM) \\
\hline & $\begin{array}{l}\text { A total of } 53 \text { participants withdrew during the study period. The most common reason for withdrawal } \\
\text { was spontaneous pregnancy }(n=23)\end{array}$ \\
\hline & 56 participants in each group (metformin and placebo) started ovulation induction (ART population: \\
\hline & 112 women) \\
\hline & Infertility factors were reported \\
\hline & Both groups were matched for age, cause and duration of infertility, weight and BMI \\
\hline & Exclusion criteria: \\
\hline & a) contraindication for starting dose of $112.5 \mathrm{IU}$ recombinant human follicle-stimulation hormone \\
\hline & b) baseline FSH serum level > $10 \mathrm{IU} / \mathrm{l}$ \\
\hline & c) liver or kidney diseases \\
\hline & d) treatment with oral glucocorticoids \\
\hline & e) congenital adrenal hyperplasia \\
\hline & f) androgen-producing tumours or Cushing's syndrome \\
\hline & g) hyperprolactinaemia \\
\hline & h) thyroid dysfunction \\
\hline & i) alcoholism or drug abuse \\
\hline & j) diabetes mellitus \\
\hline
\end{tabular}

Interventions

The dose of metformin was gradually increased from 500 to $2000 \mathrm{mg}$ per day during the first 2 weeks of treatment for at least 12 weeks prior to controlled ovarian hyperstimulation

Protocol for controlled ovarian hyperstimulation: long luteal phase pituitary down-regulation using the $\mathrm{GnRH}$ analogue nafarelin $800 \mu \mathrm{g}$ daily (Synarela ${ }^{\circledR}$ ) with rec-FSH (Gonal-f ${ }^{\circledR}$ starting dose of $112.5 \mathrm{IU}$ daily and adjusted according to ovarian response). To induce final follicular maturation, a single dose of hCG (Pregnyl ${ }^{\circledR} 5000$ or 10000 IU; or Ovitrelle ${ }^{\circledR} 250 \mu$ g) was given when at least 1 follicle reached a diameter $>17 \mathrm{~mm}$

Assisted reproductive technology (ART): IVF, ICSI or both procedures

Embryo transfer: maximum of 2 embryos were transferred per participant on day 2 or 3 after oocyte retrieval

Catheter used for transfer: not reported

Luteal phase support: progesterone, but the type and dose were selected by the physician 
Kjotrod 2011 (Continued)

\section{Outcomes}

\section{Primary outcomes:}

a) clinical pregnancy rate per woman (ITT population)

\section{Secondary outcomes:}
a) pregnancy rate
b) spontaneous pregnancy rate
c) number of collected oocytes
d) number of good-quality embryos
e) live birth rate per woman
f) incidence of OHSS
g) total dose of FSH given during stimulation
h) number of days of gonadotrophins
i) miscarriage rate
j) incidence of side effects

Notes Country of the study: Norway

\section{Risk of bias}

\begin{tabular}{|c|c|c|}
\hline Bias & Authors' judgement & Support for judgement \\
\hline $\begin{array}{l}\text { Random sequence genera- } \\
\text { tion (selection bias) }\end{array}$ & Low risk & Adequate - computer randomisation system \\
\hline $\begin{array}{l}\text { Allocation concealment } \\
\text { (selection bias) }\end{array}$ & Low risk & Adequate - codes kept by a third party in the pharmacy department \\
\hline $\begin{array}{l}\text { Blinding (performance } \\
\text { bias and detection bias) } \\
\text { All outcomes }\end{array}$ & Low risk & Double-blinded \\
\hline $\begin{array}{l}\text { Incomplete outcome data } \\
\text { (attrition bias) } \\
\text { All outcomes }\end{array}$ & Low risk & Number and reasons for withdrawals were reported \\
\hline $\begin{array}{l}\text { Selective reporting (re- } \\
\text { porting bias) }\end{array}$ & Low risk & All main outcomes were reported \\
\hline Other bias & Low risk & $\begin{array}{l}\text { Power calculation was performed. There were no significant differences in the } \\
\text { baseline characteristics of the participants between the } 2 \text { groups }\end{array}$ \\
\hline
\end{tabular}

\section{Onalan 2005}

Generation of the allocation sequence: computer randomisation system
Allocation concealment method: not reported
Blinding method: yes
Number and reasons for withdrawals: reported
ITT analysis: no


Onalan 2005 (Continued)

Prospective, randomised, double-blind, placebo-controlled trial

Metformin versus placebo

Participants 110 PCOS participants without concomitant causes of infertility
Diagnosis of PCOS followed the Rotterdam criteria (ESHRE/ASRM)
2 participants withdrew for personal reasons
108 participants were randomised (53 in the metformin group and 55 in the placebo group)
Participants < 40 years
Both groups were matched for age, duration of infertility, BMI and insulin resistance
All other causes of hyperandrogenism were ruled out before diagnosis of PCOS
Exclusion criteria: previous treatments with hormonal medications and insulin-lowering agents in the
last 3 months

Interventions Metformin $850 \mathrm{mg}$ bid or tid (according to BMI) for 8 weeks before their first ICSI cycle, through the luteal phase and until a positive pregnancy test

Protocol for controlled ovarian hyperstimulation: long luteal phase pituitary down-regulation using the $\mathrm{GnRH}$ analogue triptorelin $0.1 \mathrm{mg}$ (Decapepty $\left.{ }^{\circledR}\right)$ with rec-FSH $\left(\right.$ Gonal ${ }^{\circledR}$ starting dose of $150 \mathrm{IU}$ or $300 \mathrm{IU})$. Oocyte retrieval was performed within 36 hours after hCG injection (Pregnyl ${ }^{\circledR} 10000 \mathrm{IU}$ )

Assisted reproductive technology (ART): ICSI

Embryo transfer: maximum of 3 embryos were transferred per participant on day 3 after oocyte retrieval

A selective assisted hatching procedure with laser was used if the participant was $>35$ years, the zona pellucida was considered to be thick, abnormally shaped zona, and excessive fragmentation or slowly developing embryos were noted

Catheter used for transfer: not reported

Luteal phase support: not reported

Outcomes
a) Number of days of gonadotrophins
c) Number of ampoules of gonadotrophins
c) Number of matlure oocytes
e) Fertilisation rate
f) Number of embryos transferred
g) Pregnancy rate per woman
h) Clinical pregnancy rate per woman
i) Miscarriage rate
j) Serum E2 levels
k) Glucose/insulin rate
l) Incidence of OHSS

Notes Country of the study: Turkey

\section{Risk of bias}

\begin{tabular}{lll}
\hline Bias & Authors' judgement & Support for judgement \\
\hline $\begin{array}{l}\text { Random sequence genera- } \\
\text { tion (selection bias) }\end{array}$ & Low risk & Adequate - computer randomisation system \\
\hline $\begin{array}{l}\text { Allocation concealment } \\
\text { (selection bias) }\end{array}$ & Unclear risk & Not stated \\
\hline
\end{tabular}

Blinding (performance Low risk Double-blinded

bias and detection bias)

All outcomes

Incomplete outcome data High risk Intention-to-treat (ITT) was not performed
(attrition bias)


Onalan 2005 (Continued)

All outcomes

Selective reporting (re- Unclear risk Live birth rate was not reported
porting bias)

$\begin{array}{ll}\text { Other bias } \quad \text { Low risk } & \begin{array}{l}\text { Power calculation was not performed. There were no significant differences in } \\ \text { the baseline characteristics of the participants between the } 2 \text { groups }\end{array}\end{array}$

\section{Palomba 2011}

\section{Methods}

Generation of the allocation sequence: computer randomisation system

Allocation concealment method: random allocation sequence was concealed in the central pharmacy of the University of Catanzaro

Blinding method: yes

Number and reasons for withdrawals: no participants dropped out

ITT analysis: yes

Prospective, randomised, double-blind, placebo-controlled trial Metformin versus placebo

\section{Participants}

Number of eligible cycles: 120 infertile women with PCOS who had a history of 1 previous cancelled cycle due to a high risk of OHSS or history of a moderate or severe case of OHSS during their previous IVF cycle

Diagnosis of PCOS followed the Rotterdam criteria (ESHRE/ASRM)

120 PCOS participants were screened and underwent 120 consecutive IVF/ICSI cycles

60 participants were randomised to each group (metformin and placebo)

No participants dropped out

Age: younger than 35 years

Did not report the causes of infertility

Both groups were matched for age, median duration of infertility, BMI and hirsutism according to modified Ferriman-Gallwey score

Inclusion criteria - only participants who had received in the previous cycle:

a) mid-luteal long $\mathrm{GnRH}$ agonist and a gonadotropin step-down stimulation protocol with a starting dose of 225 IU daily

Exclusion criteria:

a) age $>35$ years

b) FSH level of $>10$

c) $\mathrm{BMI}>30 \mathrm{~kg} / \mathrm{m}^{2}$

d) neoplastic, metabolic, hepatic or cardiovascular disorders or other concurrent medical illness

e) hypothyroidism

f) hyperprolactinaemia

h) Cushing's syndrome

i) nonclassic congenital adrenal hyperplasia

j) alcohol abuse

k) current or previous: a wash-out period of at least 6 months without use of any antidiabetic, obesity or hormonal drugs except those used during the previous IVF cycle

l) male factor infertility 
Palomba 2011 (Continued) Interventions
Metformin $500 \mathrm{mg}$ tid and placebo tablets were started on the same day that down-regulation with $\mathrm{GnRH}$-agonist began and continued until a positive pregnancy test was obtained or menstrual bleeding appeared

Protocol for controlled ovarian hyperstimulation: long luteal phase pituitary down-regulation using the $\mathrm{GnRH}$ analogue Enantone $1 \mathrm{mg}^{\circledR}(0.5 \mathrm{mg}$ twice daily, $\mathrm{SC})$ and reduced to $0.5 \mathrm{mg}$ ( $0.25 \mathrm{mg}$ twice daily) after pituitary suppression with step-down rec-FSH (Gonal F ${ }^{\circledR}$ - starting dose 150 IU). hCG (Profasi ${ }^{\circledR}$ $10000 \mathrm{IU}$ ) was administered when at least 3 follicles were larger than $18 \mathrm{~mm}$. Oocyte retrieval was performed within $36 \mathrm{hrs}$ after hCG injection

Assisted reproductive technology (ART): IVF or ICSI

Embryo transfer: maximum of 2 embryos were transferred per participant on day 2, 3 or 5 after oocyte retrieval without ultrasonographic guidance

Catheter used for transfer: not reported

Luteal phase support: intramuscular progesterone (Prontogest ${ }^{\circledR}-50 \mathrm{mg} /$ day)

\section{Outcomes Primary outcomes:}

a) OHSS rate per woman

\section{Secondary outcomes:}

a) live birth rate per woman

b) clinical pregnancy rate

c) number of collected oocytes

d) number of good-quality embryos

g) total dose of FSH given during stimulation

h) number of days of gonadotrophins

Notes Country of the study: Italy

\section{Risk of bias}

\begin{tabular}{lll}
\hline Bias & Authors' judgement & Support for judgement \\
\hline $\begin{array}{l}\text { Random sequence genera- } \\
\text { tion (selection bias) }\end{array}$ & Low risk & Adequate - computer randomisation system \\
\hline $\begin{array}{l}\text { Allocation concealment } \\
\text { (selection bias) }\end{array}$ & Low risk & Random allocation sequence was concealed in the central pharmacy \\
\hline $\begin{array}{l}\text { Blinding (performance } \\
\text { bias and detection bias) } \\
\text { All outcomes }\end{array}$ & Low risk & Double-blinded \\
\hline
\end{tabular}

Incomplete outcome data Low risk There were no withdrawals
(attrition bias)

All outcomes

\begin{tabular}{|c|c|c|}
\hline $\begin{array}{l}\text { Selective reporting (re- } \\
\text { porting bias) }\end{array}$ & Low risk & All main outcomes were reported \\
\hline Other bias & High risk & $\begin{array}{l}\text { There is a discrepancy in the data in the published study: in both the Met- } \\
\text { formin group and the placebo group the clinical pregnancy rate is lower than } \\
\text { the live birth rate (pregnancy 26/60, 24/60; live birth } 29 / 60,27 / 60 \text { ). We have at- } \\
\text { tempted to contact the first author (emailed } 8 / 19 / 14 \text { ) but have not received a } \\
\text { response. }\end{array}$ \\
\hline
\end{tabular}




\begin{tabular}{l} 
Generation of allocation sequence: not reported \\
Allocation concealment method: not reported \\
Blinding method: yes \\
Number and reasons for withdrawals: there were no withdrawals \\
ITT analysis: yes \\
Prospective, randomised, double-blind, placebo-controlled trial \\
Metformin versus placebo \\
$\begin{array}{l}66 \text { clomiphene citrate-resistant PCOS participants were randomised (34 in the metformin group and } 32 \\
\text { in the placebo group) } \\
\text { Diagnosis of PCOS followed the Rotterdam criteria (ESHRE/ASRM) } \\
\text { 34 women in the metformin group and } 32 \text { in the placebo group started controlled ovarian hyperstimu- } \\
\text { lation (66 participants - } 4 \text { women in the metformin group and } 2 \text { in the placebo group became pregnant } \\
\text { spontaneously) } \\
\text { There were no withdrawals } \\
\text { Infertility factors were reported } \\
\text { Both groups were matched for age, cause and duration of infertility, BMI and hormonal/ biochemical } \\
\text { profiles } \\
\text { All participants were required to have a normal uterine cavity }\end{array}$ \\
\hline
\end{tabular}

Interventions Metformin $850 \mathrm{mg}$ tid for a month before their first ICSI cycle, through the luteal phase and until a positive pregnancy test. If the test was positive metformin was continued until 12 weeks of gestation Protocol for controlled ovarian hyperstimulation: long luteal phase pituitary down-regulation using the $\mathrm{GnRH}$ analogue triptorelin (Decapepty ${ }^{\circledR}$ ) with human menopausal gonadotropin - HMG (Menogon ${ }^{\circledR}$ ) (starting dose of $150 \mathrm{IU}$ daily and adjusted according to ovarian response). Oocyte retrieval was performed within 36 hrs after hCG injection (10000 IU)

Assisted reproductive technology (ART): IVF or ICSI

Embryo transfer: 2 to 4 embryos were transferred per participant on day 3 after oocyte retrieval Luteal phase support: progesterone pessaries (Cyclogest ${ }^{\circledR}$ )

autcomes Number of days of gonadotrophins
b) Number of ampoules of gonadotrophins
c) Number of follicles $(>14 \mathrm{~mm})$
d) Number of mature oocytes
e) Fertilisation rate
f) Number of embryo transferred
g) Pregnancy rate per woman
h) Clinical pregnancy rate per woman
i) Miscarriage rate
j) Serum E2 levels on day of hCG
k) Glucose/insulin rate
l) Incidence of OHSS

Notes

Country of the study: Jordan

\section{Risk of bias}


Qublan 2009 (Continued)

\begin{tabular}{|c|c|c|}
\hline Bias & Authors' judgement & Support for judgement \\
\hline $\begin{array}{l}\text { Random sequence genera- } \\
\text { tion (selection bias) }\end{array}$ & Unclear risk & Not stated \\
\hline $\begin{array}{l}\text { Allocation concealment } \\
\text { (selection bias) }\end{array}$ & Unclear risk & Not stated \\
\hline $\begin{array}{l}\text { Blinding (performance } \\
\text { bias and detection bias) } \\
\text { All outcomes }\end{array}$ & High risk & Single-blinded \\
\hline $\begin{array}{l}\text { Incomplete outcome data } \\
\text { (attrition bias) } \\
\text { All outcomes }\end{array}$ & Low risk & Intention-to-treat (ITT) was performed \\
\hline $\begin{array}{l}\text { Selective reporting (re- } \\
\text { porting bias) }\end{array}$ & Unclear risk & Live birth rate was not reported \\
\hline Other bias & Low risk & $\begin{array}{l}\text { Power calculation was performed. There were no significant differences in the } \\
\text { baseline characteristics of the participants between the } 2 \text { groups }\end{array}$ \\
\hline
\end{tabular}

Tang 2006

\begin{tabular}{|c|c|}
\hline \multirow[t]{6}{*}{ Methods } & Generation of allocation sequence: reported \\
\hline & Allocation concealment method: reported \\
\hline & Blinding method: yes \\
\hline & Number and reasons for withdrawals: reported \\
\hline & ITT analysis: yes \\
\hline & $\begin{array}{l}\text { Prospective, randomised, double-blind, placebo-controlled trial } \\
\text { Metformin versus placebo }\end{array}$ \\
\hline \multirow[t]{2}{*}{ Participants } & $\begin{array}{l}\text { Diagnosis of PCOS followed the Rotterdam criteria (ESHRE/ASRM) } \\
101 \text { PCOS participants were randomised ( } 52 \text { in the metformin group and } 49 \text { in the placebo group) }\end{array}$ \\
\hline & $\begin{array}{l}5 \text { cycles in the metformin group and } 2 \text { in the placebo group were abandoned due to poor response } \\
47 \text { cycles in each arm completed through to oocyte retrieval } \\
\text { Age: } 20 \text { to } 39 \text { years } \\
\text { Did not report the causes of infertility } \\
\text { Both groups were matched for mean age, median duration of infertility, BMI, nulliparity, participants } \\
\text { who had previous IVF cycle, ICSI cycles } \\
\text { Inclusion criteria: } \\
\text { a) serum testosterone concentration }<5.0 \mathrm{nmol} / \mathrm{l} \\
\text { b) normal prolactin concentration, thyroid, renal and haematological indices } \\
\text { Exclusion criteria: } \\
\text { a) concurrent hormone therapy within the previous } 6 \text { weeks } \\
\text { b) any chronic disease that could interfere with the absorption, distribution, metabolism or excretion } \\
\text { of metformin } \\
\text { c) renal or liver disease } \\
\text { d) systemic disease or diabetes (types } 1 \text { and 2) }\end{array}$ \\
\hline
\end{tabular}


Tang 2006 (Continued)

Protocol for controlled ovarian hyperstimulation: long luteal phase pituitary down-regulation using the $\mathrm{GnRH}$ analogue nafarelin $600 \mu \mathrm{g}$ daily $\left(\right.$ Synare $^{\circledR}{ }^{\circledR}$ ) with step up rec-FSH (Puregon ${ }^{\circledR}$ starting dose of $100 \mathrm{IU}$ ). hCG (Profasi ${ }^{\circledR} 10000 \mathrm{IU}$ ) was administered when there were more than 3 follicles over $17 \mathrm{~mm}$ in diameter

Oocyte retrieval was performed within 36 to $38 \mathrm{hrs}$ after hCG injection

All follicles with a diameter over $14 \mathrm{~mm}$ were aspirated and flushed twice with normal saline when oocytes were not found in the first aspirate

Assisted reproductive technology (ART): IVF or ICSI (4 hours after oocyte retrieval)

Embryo transfer: maximum of 2 embryos were transferred per participant on day 2 after follicle puncture under abdominal US guidance

Catheter used for transfer: Wallace

Luteal phase support: daily Cyclogest ${ }^{\circledR}$ pessary $(400 \mathrm{mg}$ ) was used until the day of pregnancy test

Putcomes
Primary outcome:
Secondilisation rate
a) number outcomes:
b) total dose of FSH given during stimulation
c) number of follicles (>14 mm)
d) number of oocytes
e) number of embryos transferred
f) implantation rate
g) pregnancy rate per woman
h) clinical pregnancy rate per woman
i) pregnancy rate per transfer
j) clinical pregnancy rate per transfer
k) live birth rate
l) incidence of OHSS that required hospitalisation
m) side effects
n) fasting insulin
o) fasting glucose
p) SHBG
q) free androgen index
r) testosterone

Notes Country of the study: United Kingdom

\section{Risk of bias}

\begin{tabular}{lll}
\hline Bias & Authors' judgement & Support for judgement \\
\hline $\begin{array}{l}\text { Random sequence genera- } \\
\text { tion (selection bias) }\end{array}$ & Low risk & Adequate - random numbers table \\
\hline $\begin{array}{l}\text { Allocation concealment } \\
\text { (selection bias) }\end{array}$ & Low risk & Adequate - codes kept by a third party in the trial office \\
\hline
\end{tabular}

Blinding (performance Low risk Double-blinded

bias and detection bias)

All outcomes

Incomplete outcome data Low risk $\quad$ Reasons for withdrawals were reported. ITT analysis was performed
(attrition bias)

All outcomes

Selective reporting (re- Low risk $\quad$ All main outcomes were reported
porting bias)


Tang 2006 (Continued)

Other bias Low risk Power calculation was performed. There were no significant differences in the baseline characteristics of the participants between the 2 groups

Visnova 2003

Gethods
Allocation concealment method: not reported
Blinding method: no
Number and reasons for withdrawals: reported
ITT analysis: yes
Prospective randomised controlled trial
Metformin versus no treatment

Participants

172 participants were selected but only 141 were randomised because they met the inclusion criteria for PCOS according to the Rotterdam criteria (ESHRE/ASRM)

72 participants in the metformin group (I), 69 in the no treatment group (II) and 31 in the no PCOS participants group (III) started controlled ovarian hyperstimulation

1 participant in the metformin group (I) and 3 in the no treatment group (II) were excluded due to a poor response to ovulation induction

Infertility factors were not reported

Both groups were matched for age, BMI and hormonal parameters

Exclusion criteria:

if the participant did not met the PCOS diagnostic criteria

Metformin 500 mg bid from the first day of ov
Protocol for ovulation induction: long protocolions
day)
The following were not reported:
a) which hCG was used
b) when the oocyte retrieval was performed
c) how many embryos were transferred
d) luteal phase support medication used

\begin{tabular}{ll}
\hline Outcomes & a) Incidence of OHSS \\
b) Pregnancy rate \\
c) Number of oocytes retrieved \\
d) Total dose of FSH (IU) \\
e) Number of days of gonadotrophin treatment
\end{tabular}

Notes Country of the study: Czech Republic

\section{Risk of bias}

\begin{tabular}{lll}
\hline Bias & Authors' judgement & Support for judgement \\
\hline $\begin{array}{l}\text { Random sequence genera- } \\
\text { tion (selection bias) }\end{array}$ & Unclear risk & Not reported \\
\hline $\begin{array}{l}\text { Allocation concealment } \\
\text { (selection bias) }\end{array}$ & Unclear risk & Not stated \\
\hline $\begin{array}{l}\text { Blinding (performance } \\
\text { bias and detection bias) }\end{array}$ & High risk & Not blinded \\
\hline
\end{tabular}

Metformin treatment before and during IVF or ICSI in women with polycystic ovary syndrome (Review) 
Visnova 2003 (Continued)

All outcomes

$\begin{array}{ll}\begin{array}{l}\text { Incomplete outcome data } \\ \text { (attrition bias) }\end{array} & \text { Low risk } \\ \text { All outcomes } & \begin{array}{l}\text { Reasons for withdrawals were reported. However, } 4 \text { participants were exclud- } \\ \text { ed due to poor response to ovulation induction after randomisation and were } \\ \text { not included in the ITT by study }\end{array}\end{array}$

All outcomes

Live birth rate was not assessed

Selective reporting (re- Unclear risk Live birth rate was not assessed
porting bias)

Other bias Unclear risk No power calculation was performed. Infertility factors were not reported

AMH: anti-Müllerian hormone

ART: assisted reproductive technology

bid: twice a day

BMI: body mass index

$\mathrm{Cl}$ : confidence interval

E2: oestradiol

FSH: follicle-stimulating hormone

$\mathrm{GnRH}$ : gonadotrophin-releasing hormone

hCG: human chorionic gonadotrophin

ICSI: intracytoplasmic sperm injection

ITT: intention-to-treat

IU: international units

IVF: in vitro fertilisation

OCP: oral contraceptive pill

OHSS: ovarian hyperstimulation syndrome

OR: odds ratio

PCOS: polycystic ovarian syndrome

$\mathrm{RCT}$ : randomised controlled trial

SC: subcutaneous

SD: standard deviation

SE: standard error

SHBG: sex hormone-binding globulin

tid: three times a day

US: ultrasonography

Characteristics of excluded studies [ordered by study ID]

\begin{tabular}{ll}
\hline Study & Reason for exclusion \\
\hline Demirol 2006 & Not a randomised controlled trial \\
\hline Egbase 2001 & $\begin{array}{l}\text { Data were not properly reported. The study did not state how many participants withdrew from } \\
\text { each group (1 and 2). Moreover, the author does not present the means and standard deviations } \\
\text { (SD) nor the standard errors (SE) }\end{array}$ \\
\hline
\end{tabular}

Geusa 2002

The study was excluded because of data irregularities (summarised reported data were not consistent with table data). We were not successful in contacting the authors to clarify the queries

Kahraman $2001 \quad$ Control group was treated with oral contraceptives instead of placebo or no treatment

\begin{tabular}{ll}
\hline Palomba 2011b & Participants were poor responder women \\
\hline Schachter 2007 & Participants specifically undergoing ICSI were not randomised separately \\
\hline Stadtmauer 1999 & $\begin{array}{l}\text { It is not a randomised controlled trial } \\
\text { Prospective controlled analysis }\end{array}$ \\
\hline
\end{tabular}




\begin{tabular}{ll}
\hline Study & Reason for exclusion \\
\hline Stadtmauer 2001 & Participants acted as their own control, when metformin was used in the subsequent cycle \\
\hline Stadtmauer 2002 & The study is not a randomised controlled trial \\
\hline Tasdemir 2004 & Participants undergoing ovulation induction cycles; not IVF or ICSI cycles \\
\hline
\end{tabular}

ICSI: intracytoplasmic sperm injection

IVF: in vitro fertilisation

Characteristics of studies awaiting assessment [ordered by study ID]

Tang 2010

\begin{tabular}{ll}
\hline Methods & Randomised controlled trial \\
\hline Participants & 69 PCOS participants were randomised (39 in the metformin group and 38 in the placebo group) \\
\hline Interventions & Metformin versus placebo \\
\hline Outcomes & $\begin{array}{l}\text { Live birth rate; fertilisation rate; number of follicles; number of oocytes; number of embryos trans- } \\
\text { ferred; clinical pregnancy rate per woman; incidence of OHSS }\end{array}$ \\
\hline Notes & $\begin{array}{l}\text { Information retrieved from abstract of congress. Authors were contacted to give more information. } \\
\text { We are awaiting more details to classify the study }\end{array}$ \\
\hline
\end{tabular}

PCOS: polycystic ovarian syndrome

\section{DATA AND ANALYSES}

\section{Comparison 1. Metformin versus placebo or no treatment}

\begin{tabular}{lllll}
\hline Outcome or subgroup title & $\begin{array}{l}\text { No. of } \\
\text { studies }\end{array}$ & $\begin{array}{l}\text { No. of } \\
\text { partici- } \\
\text { pants }\end{array}$ & Statistical method & Effect size \\
\hline 1 Live birth rate per woman & 5 & 551 & Odds Ratio $(\mathrm{M}-\mathrm{H}$, Random, 95\% Cl) & $1.39[0.81,2.40]$ \\
\hline $\begin{array}{l}1.1 \text { Long protocol GnRH ago- } \\
\text { nist }\end{array}$ & 5 & 551 & Odds Ratio (M-H, Random, 95\% Cl) & $1.39[0.81,2.40]$ \\
\hline $\begin{array}{l}2 \text { Clinical pregnancy rate per } \\
\text { woman }\end{array}$ & 8 & 775 & Odds Ratio (M-H, Random, 95\% $\mathrm{Cl})$ & $1.52[1.07,2.15]$ \\
\hline $\begin{array}{l}2.1 \text { Long protocol GnRH ago- } \\
\text { nist }\end{array}$ & 8 & 775 & Odds Ratio (M-H, Random, 95\% Cl) & $1.52[1.07,2.15]$ \\
\hline $\begin{array}{l}3 \text { Incidence of OHSS per } \\
\text { woman }\end{array}$ & 8 & 798 & Odds Ratio (M-H, Random, 95\% Cl) & $0.29[0.18,0.49]$ \\
\hline
\end{tabular}




\begin{tabular}{|c|c|c|c|c|}
\hline Outcome or subgroup title & $\begin{array}{l}\text { No. of } \\
\text { studies }\end{array}$ & $\begin{array}{l}\text { No. of } \\
\text { partici- } \\
\text { pants }\end{array}$ & Statistical method & Effect size \\
\hline $\begin{array}{l}\text { 3.1 Long protocol GnRH ago- } \\
\text { nist }\end{array}$ & 7 & 758 & Odds Ratio (M-H, Random, 95\% Cl) & $0.29[0.16,0.51]$ \\
\hline $\begin{array}{l}\text { 3.2 Short protocol GnRH an- } \\
\text { tagonist }\end{array}$ & 1 & 40 & Odds Ratio (M-H, Random, 95\% Cl) & $0.30[0.03,3.15]$ \\
\hline 4 Miscarriage rate per woman & 6 & 521 & Odds Ratio (M-H, Random, 95\% Cl) & $0.76[0.43,1.37]$ \\
\hline $\begin{array}{l}4.1 \text { Long protocol GnRH ago- } \\
\text { nist }\end{array}$ & 6 & 521 & Odds Ratio (M-H, Random, 95\% Cl) & $0.76[0.43,1.37]$ \\
\hline 5 Side effects per woman & 4 & 431 & Odds Ratio (M-H, Random, $95 \% \mathrm{Cl})$ & $4.49[1.88,10.72]$ \\
\hline $\begin{array}{l}5.1 \text { Long protocol GnRH ago- } \\
\text { nist }\end{array}$ & 4 & 431 & Odds Ratio (M-H, Random, 95\% Cl) & $4.49[1.88,10.72]$ \\
\hline $\begin{array}{l}6 \text { Number of oocytes retrieved } \\
\text { per woman }\end{array}$ & 8 & 635 & Mean Difference (IV, Random, 95\% CI) & $-0.76[-2.02,0.50]$ \\
\hline $\begin{array}{l}6.1 \text { Long protocol with GnRH } \\
\text { agonist }\end{array}$ & 7 & 595 & Mean Difference (IV, Random, 95\% Cl) & $-0.67[-2.12,0.79]$ \\
\hline $\begin{array}{l}6.2 \text { Short protocol with } \mathrm{GnRH} \\
\text { antagonist }\end{array}$ & 1 & 40 & Mean Difference (IV, Random, 95\% CI) & $-1.0[-3.95,1.95]$ \\
\hline $\begin{array}{l}7 \text { Mean total dose of FSH (IU) } \\
\text { per woman }\end{array}$ & 8 & & Mean Difference (IV, Random, 95\% CI) & Totals not selected \\
\hline $\begin{array}{l}7.1 \text { Long protocol with GnRH } \\
\text { agonist }\end{array}$ & 7 & & Mean Difference (IV, Random, 95\% CI) & $0.0[0.0,0.0]$ \\
\hline $\begin{array}{l}\text { 7.2 Short protocol with } \mathrm{GnRH} \\
\text { antagonist }\end{array}$ & 1 & & Mean Difference (IV, Random, 95\% CI) & $0.0[0.0,0.0]$ \\
\hline $\begin{array}{l}8 \text { Mean days of gonadotrophin } \\
\text { per woman }\end{array}$ & 8 & 643 & Mean Difference (IV, Random, 95\% CI) & $-0.19[-0.77,0.40]$ \\
\hline $\begin{array}{l}8.1 \text { Long protocol with } \mathrm{GnRH} \\
\text { agonist }\end{array}$ & 7 & 603 & Mean Difference (IV, Random, 95\% CI) & $-0.22[-0.89,0.45]$ \\
\hline $\begin{array}{l}8.2 \text { Short protocol with } \mathrm{GnRH} \\
\text { antagonist }\end{array}$ & 1 & 40 & Mean Difference (IV, Random, 95\% CI) & $0.0[-1.30,1.30]$ \\
\hline $\begin{array}{l}9 \text { Cycle cancellation rate (after } \\
\text { ovulation induction) }\end{array}$ & 6 & 624 & Odds Ratio (M-H, Random, 95\% Cl) & $0.64[0.32,1.28]$ \\
\hline $\begin{array}{l}\text { 9.1 Long protocol with GnRH } \\
\text { agonist }\end{array}$ & 5 & 584 & Odds Ratio (M-H, Random, 95\% Cl) & $0.67[0.31,1.45]$ \\
\hline $\begin{array}{l}9.2 \text { Short protocol with } \mathrm{GnRH} \\
\text { antagonist }\end{array}$ & 1 & 40 & Odds Ratio (M-H, Random, 95\% Cl) & $0.30[0.03,3.15]$ \\
\hline $\begin{array}{l}10 \text { Serum oestradiol level } \\
(\mathrm{nmol} / \mathrm{l}) \text { per woman }\end{array}$ & 5 & & Mean Difference (IV, Random, 95\% CI) & Totals not selected \\
\hline
\end{tabular}




\begin{tabular}{lllll}
\hline Outcome or subgroup title & $\begin{array}{l}\text { No. of } \\
\text { studies }\end{array}$ & $\begin{array}{l}\text { No. of } \\
\text { partici- } \\
\text { pants }\end{array}$ & Statistical method & Effect size \\
\hline $\begin{array}{l}10.1 \text { Long protocol with GnRH } \\
\text { agonist }\end{array}$ & 4 & Mean Difference (IV, Random, $95 \% \mathrm{Cl})$ & $0.0[0.0,0.0]$ \\
\hline $\begin{array}{l}10.2 \text { Short protocol with GnRH } \\
\text { antagonist }\end{array}$ & 1 & Mean Difference (IV, Random, $95 \% \mathrm{Cl})$ & $0.0[0.0,0.0]$ \\
\hline $\begin{array}{l}11 \text { Mean or median serum an- } \\
\text { drogen levels per woman }\end{array}$ & Other data & No numeric data \\
\hline $\begin{array}{l}12 \text { Mean or median fasting in- } \\
\text { sulin and glucose levels per } \\
\text { woman }\end{array}$ & Other data & No numeric data \\
\hline
\end{tabular}

\section{Analysis 1.1. Comparison 1 Metformin versus placebo or no treatment, Outcome 1 Live birth rate per woman.}

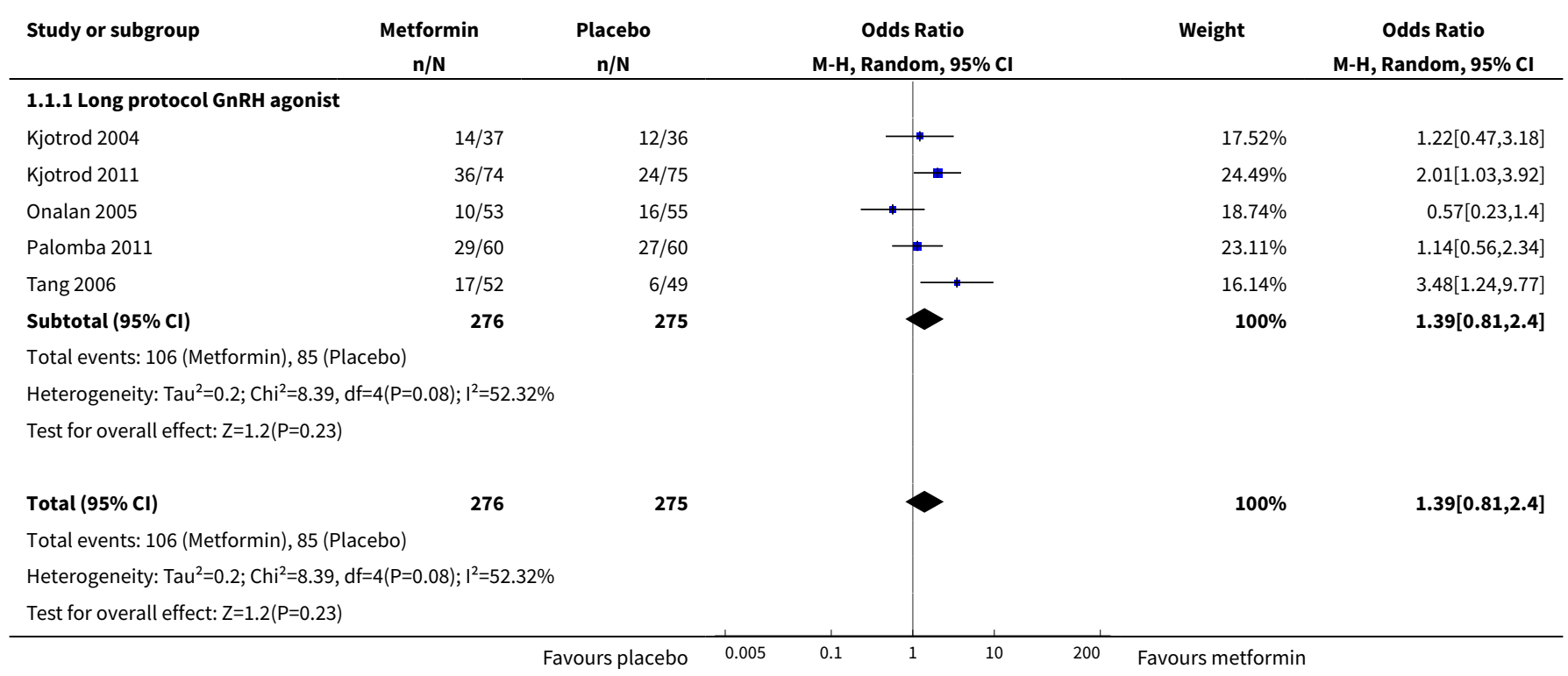

\section{Analysis 1.2. Comparison 1 Metformin versus placebo or no treatment, Outcome 2 Clinical pregnancy rate per woman.}

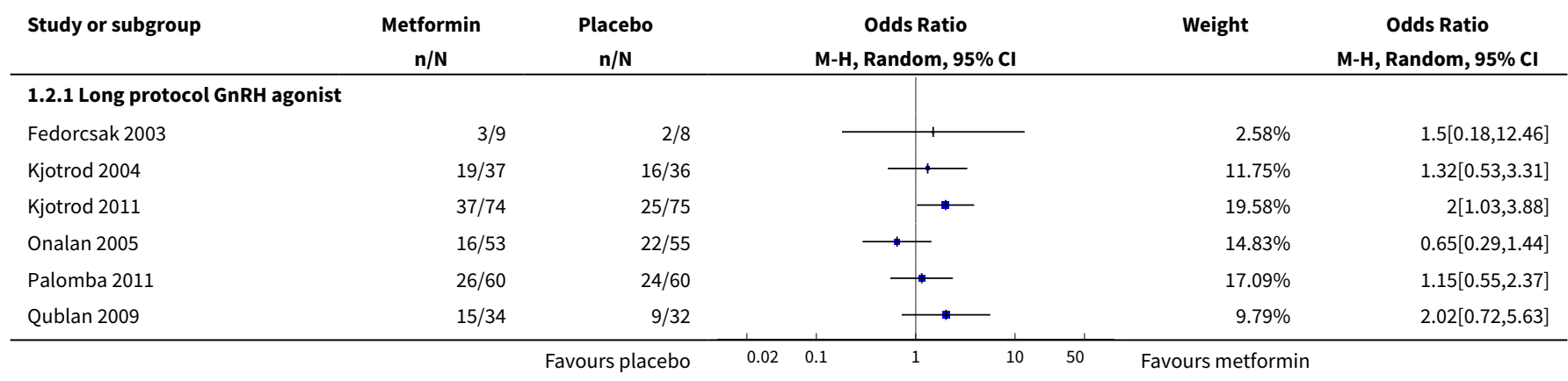




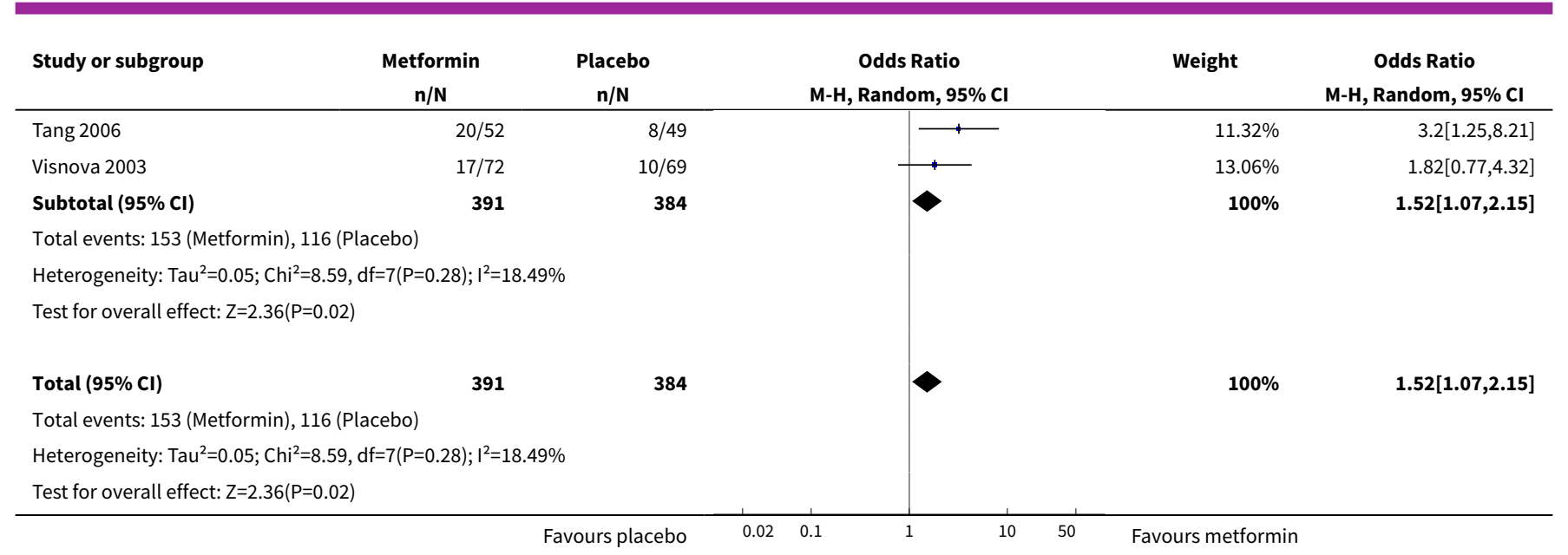

\section{Analysis 1.3. Comparison 1 Metformin versus placebo or no treatment, Outcome 3 Incidence of OHSS per woman.}

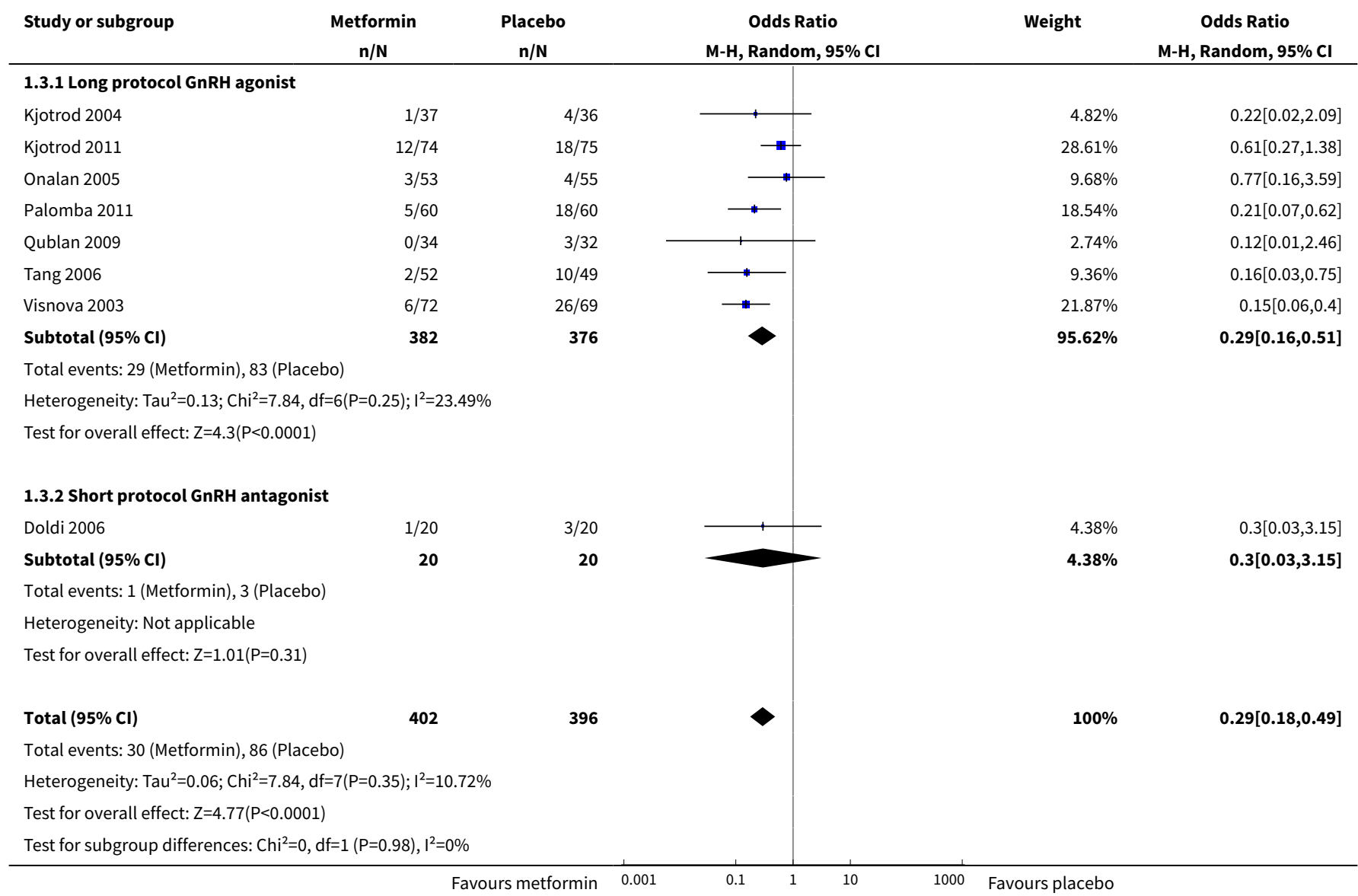


Analysis 1.4. Comparison 1 Metformin versus placebo or no treatment, Outcome 4 Miscarriage rate per woman.

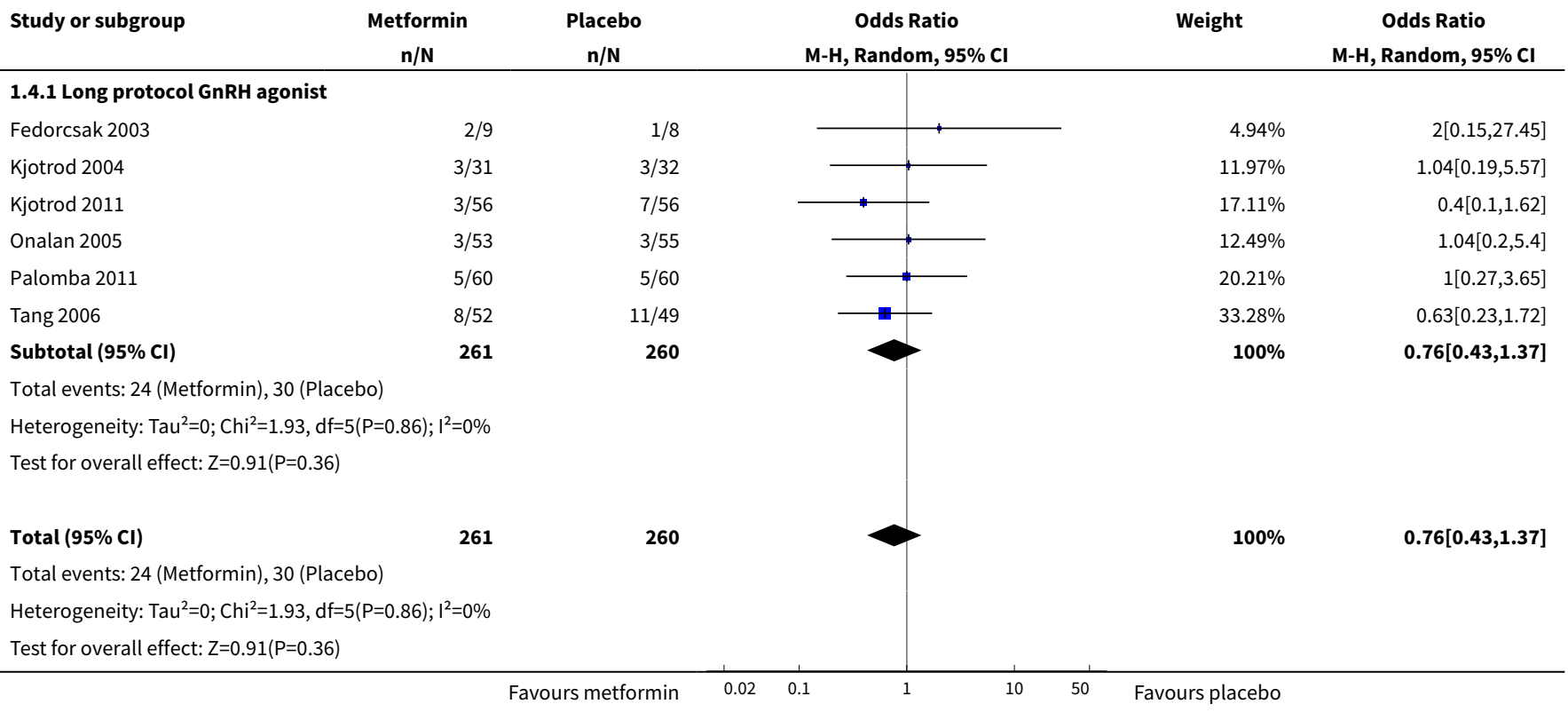

Analysis 1.5. Comparison 1 Metformin versus placebo or no treatment, Outcome 5 Side effects per woman.

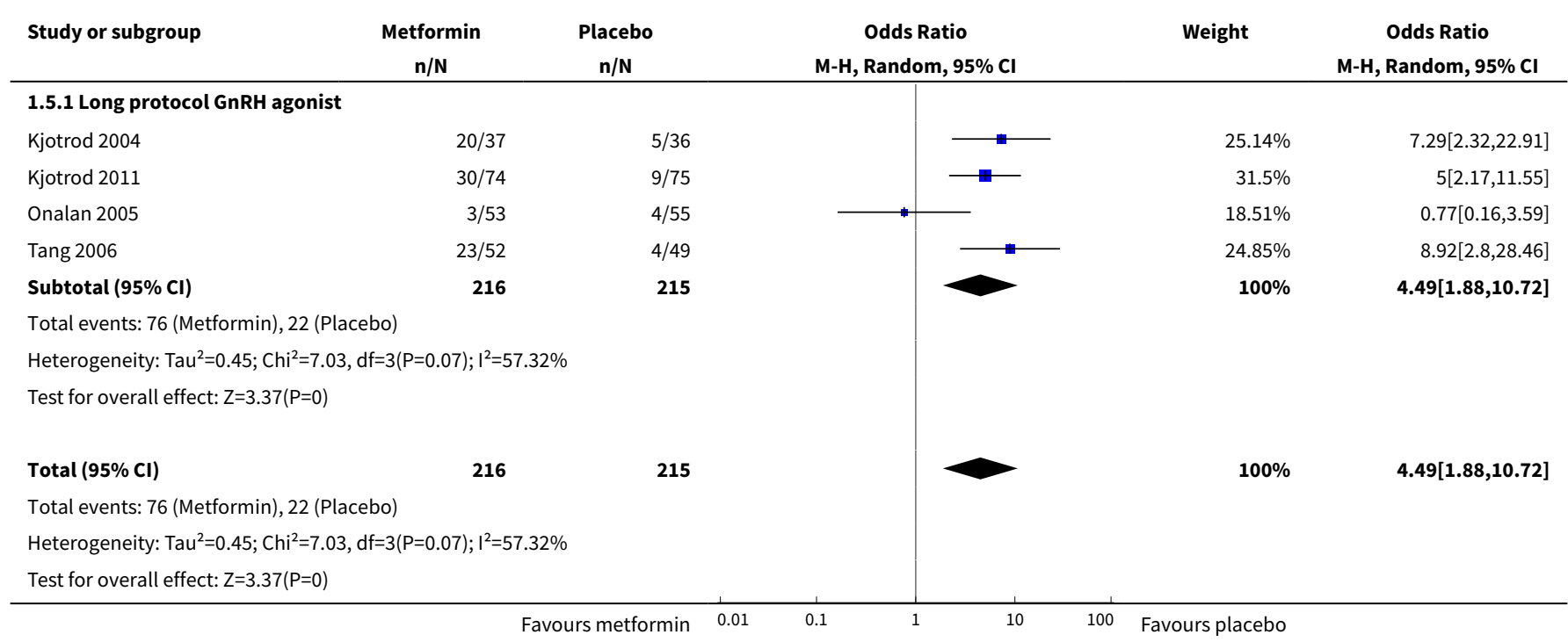

Analysis 1.6. Comparison 1 Metformin versus placebo or no treatment, Outcome 6 Number of oocytes retrieved per woman.

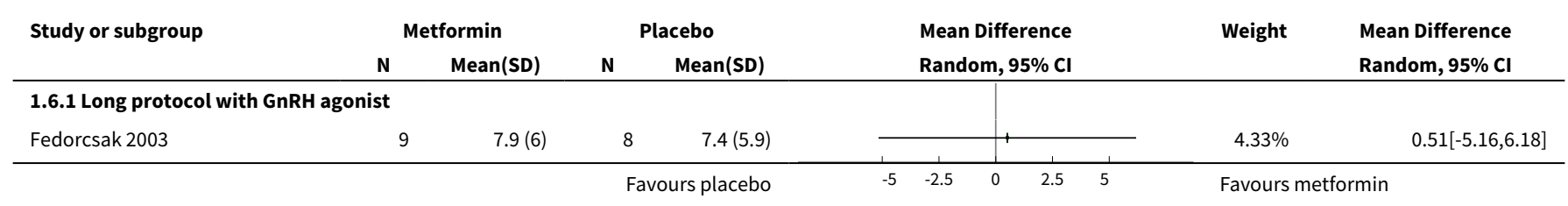




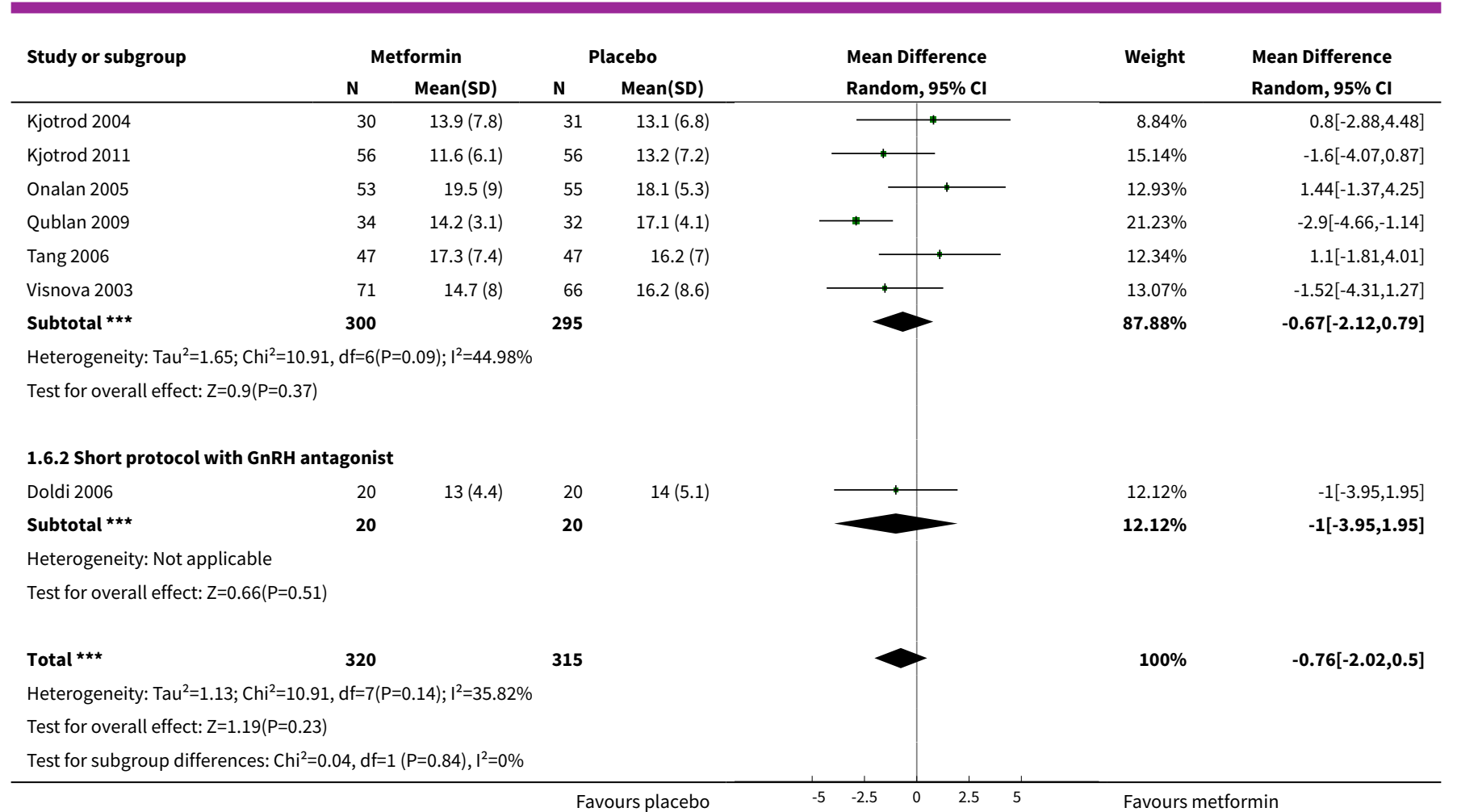

\section{Analysis 1.7. Comparison 1 Metformin versus placebo or no treatment, Outcome 7 Mean total dose of FSH (IU) per woman.}

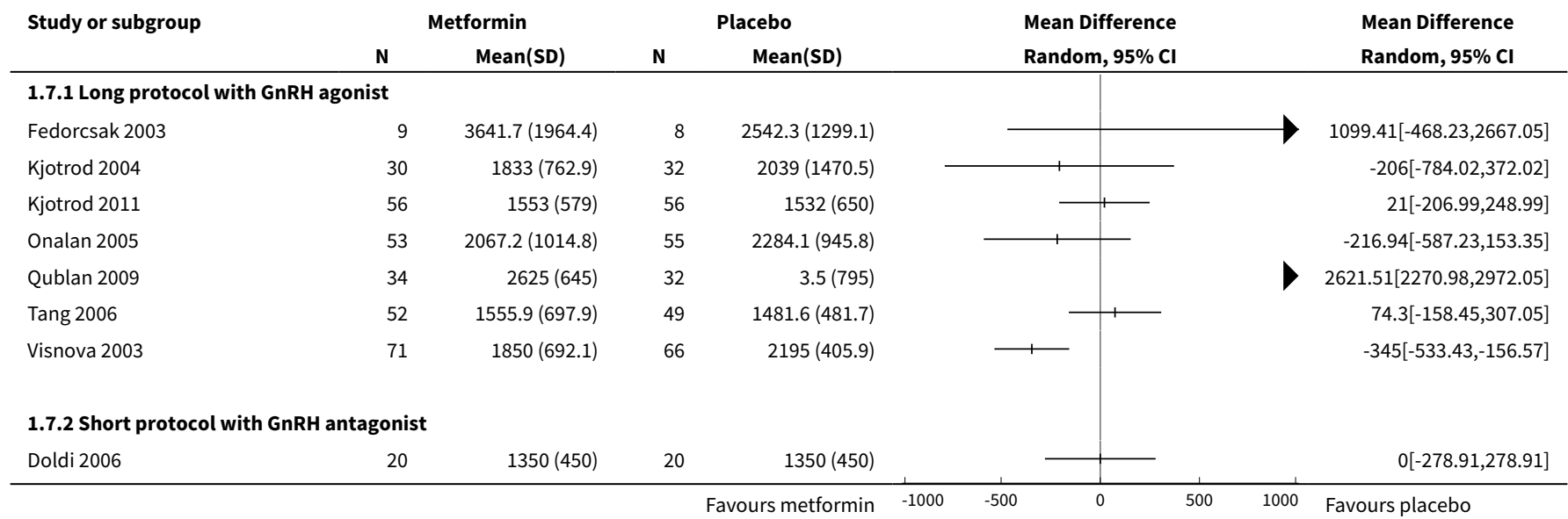

Analysis 1.8. Comparison 1 Metformin versus placebo or no treatment, Outcome 8 Mean days of gonadotrophin per woman.

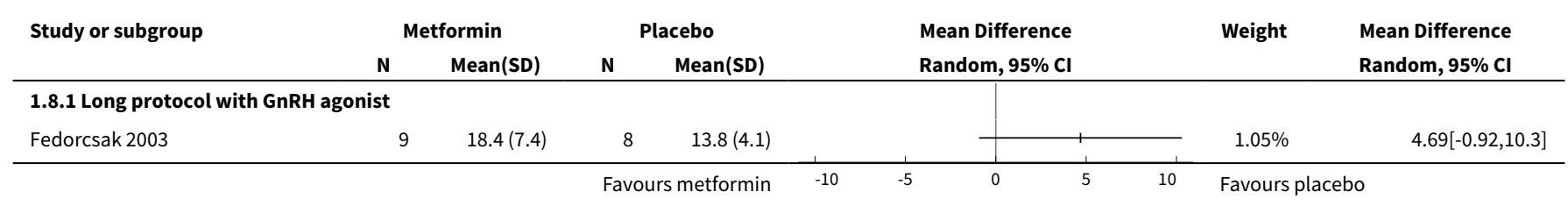




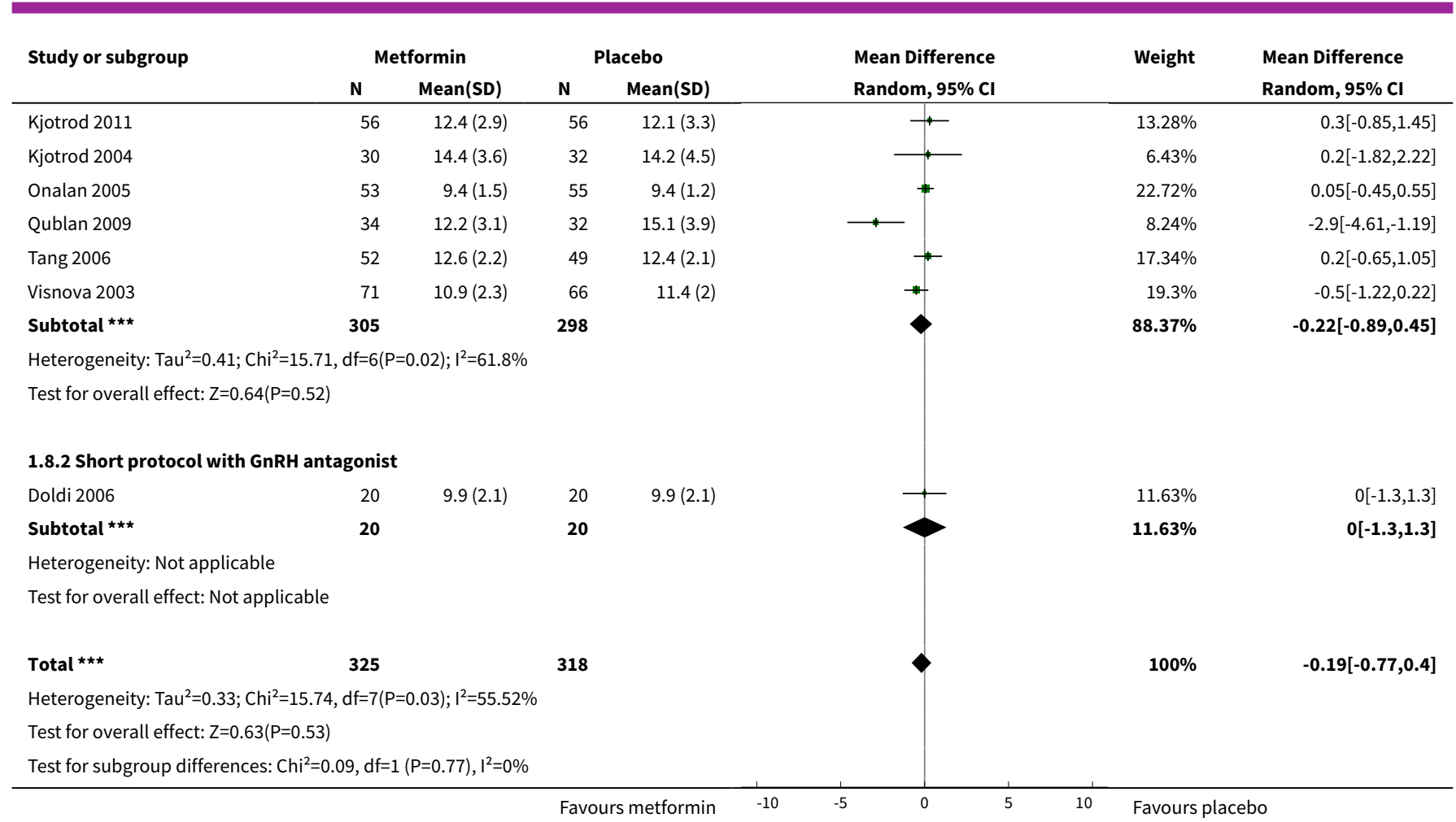

Analysis 1.9. Comparison 1 Metformin versus placebo or no treatment, Outcome 9 Cycle cancellation rate (after ovulation induction).

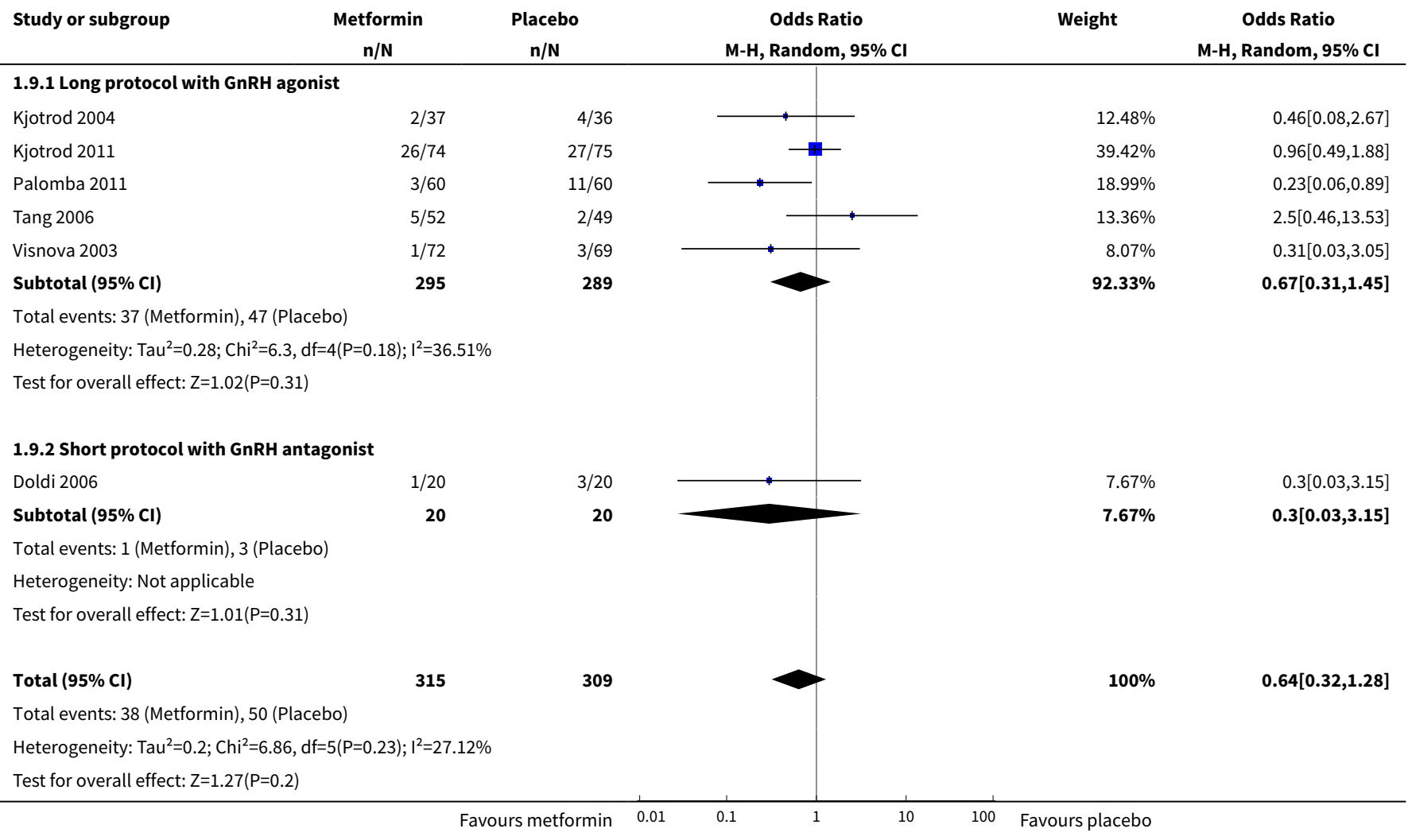




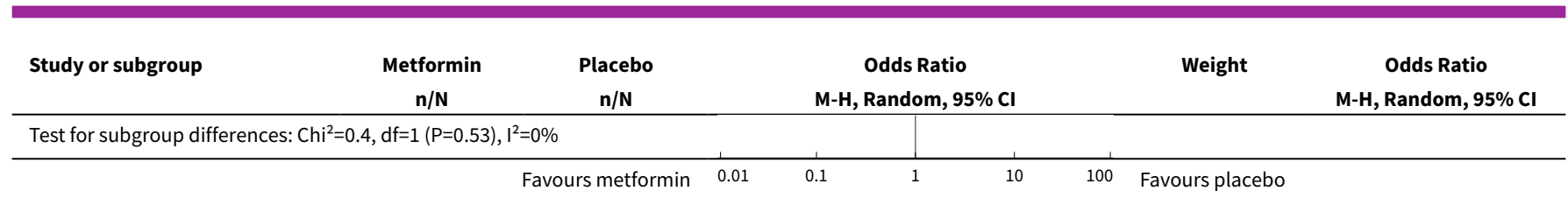

Analysis 1.10. Comparison 1 Metformin versus placebo or no treatment, Outcome 10 Serum oestradiol level ( $\mathrm{nmol} / \mathrm{l}$ ) per woman.

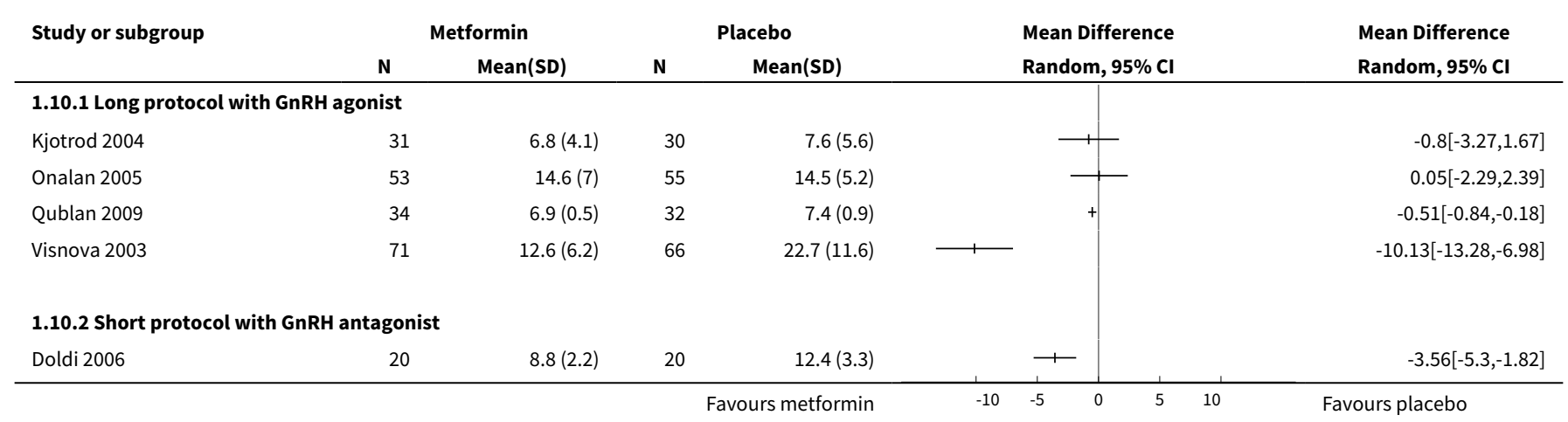

Analysis 1.11. Comparison 1 Metformin versus placebo or no treatment, Outcome 11 Mean or median serum androgen levels per woman.

\begin{tabular}{|c|c|c|c|}
\hline \multicolumn{4}{|c|}{ Mean or median serum androgen levels per woman } \\
\hline Study & Results & Metformin & Placebo \\
\hline Onalan 2005 & $\begin{array}{l}\text { No significant differences in total } \\
\text { testosterone measures from women } \\
\text { treated with placebo }(P=0.646)\end{array}$ & Median 3.1 ; range 2.5 to 3.9 & Median 3.1 ; range 2.4 to 3 \\
\hline Tang 2006 & $\begin{array}{l}\text { Testosterone levels did not change } \\
\text { significantly in the group taking met- } \\
\text { formin }(P=0.892) \text {; however, partici- } \\
\text { pants in the placebo group had a signif- } \\
\text { icant increase in testosterone levels ( } P \\
=0.040) \text {. In the metformin group, on the } \\
\text { day of hCG administration, there was } \\
\text { a significant decrease in testosterone } \\
\text { concentration }(P=0.029) \text { and in the } \\
\text { free-androgen index }(P=0.004)\end{array}$ & $\begin{array}{l}\text { Baseline geometric mean: } 2.03 \mathrm{nmol} / \mathrm{l} \text {, } \\
\text { geometric mean on the day of } \mathrm{hCG} \text { ad- } \\
\text { ministration: } 1.97 \mathrm{nmol} / \mathrm{l} \text {. Testosterone } \\
\text { concentration (geometric mean: } 1.96 \\
\mathrm{nmol} / \mathrm{l} \text { ). Free-androgen index (geomet- } \\
\text { ric mean: } 2.43 \text { ) }\end{array}$ & $\begin{array}{l}\text { Baseline geometric mean: } 2.06 \mathrm{nmol} / \mathrm{l} \text {, } \\
\text { geometric mean on the day of } \mathrm{hCG} \text { ad- } \\
\text { ministration: } 2.52 \mathrm{nmol} / \mathrm{l} \text {. Testosterone } \\
\text { concentration (geometric mean: } 2.52 \\
\text { nmol/l). Free-androgen index (geomet- } \\
\text { ric mean: } 3.34 \text { ) }\end{array}$ \\
\hline
\end{tabular}

Analysis 1.12. Comparison 1 Metformin versus placebo or no treatment, Outcome 12 Mean or median fasting insulin and glucose levels per woman.

\begin{tabular}{|c|c|c|c|}
\hline \multicolumn{4}{|c|}{ Mean or median fasting insulin and glucose levels per woman } \\
\hline Study & Results & Metformin & Placebo \\
\hline Onalan 2005 & $\begin{array}{l}\text { There were no significant changes } \\
\text { in the glucose/insulin ratio between } \\
\text { groups }(P=0.81)\end{array}$ & Median 6 ; range 2.4 to 8.8 & Median 6; range 3 to 10 \\
\hline Tang 2006 & $\begin{array}{l}\text { There were no significant changes in } \\
\text { the insulin sensitivity test (QUICKI) be- } \\
\text { tween baseline and the day of oocyte } \\
\text { retrieval in the metformin group ( } P \\
=0.200 \text { ) and the placebo group }(P= \\
0.572) \text {. }\end{array}$ & $\begin{array}{l}\text { Baseline: } 0.377 \\
\text { At the day of oocyte retrieval: } 0.417\end{array}$ & $\begin{array}{l}\text { Baseline: } 0.386 \\
\text { At the day of oocyte retrieval: } 0.400\end{array}$ \\
\hline
\end{tabular}




\section{AP PEN DICES}

\section{Appendix 1. Search strategies}

\section{Database: Cochrane Menstrual Disorders and Subfertility Group Specialised Register}

\section{Search strategy}

Keywords CONTAINS "PCOS" or "polycystic ovary syndrome" or "Polycystic Ovary Syndrome" or Title CONTAINS "PCOS" or "polycystic ovary syndrome" or "Polycystic Ovary Syndrome"

AND

Keywords CONTAINS "IVF" or "in-vitro fertilisation " or "in vitro fertilization" or "ICSI" or "intracytoplasmic morphologically selected sperm injection" or "intracytoplasmic sperm injection" or "Embryo Transfer" or "ovulation" or "ovarian stimulation" or Title CONTAINS "IVF" or "in-vitro fertilisation " or "in vitro fertilization" or "ICSI" or "intracytoplasmic morphologically selected sperm injection" or "intracytoplasmic sperm injection" or "Embryo Transfer" or "ovulation" or "ovarian stimulation"

AND

Keywords CONTAINS "metformin" or Title CONTAINS "metformin"

\section{Database: MEDLINE via OVID <1980 to 20 October 2014>}

\section{Search strategy}

1 exp Polycystic Ovary Syndrome/ (10671)

2 Polycystic Ovar\$.tw. (11225)

3 (PCOS or PCOD).tw. (6980)

4 (stein-leventhal or leventhal).tw. (694)

5 (ovar\$ adj (scelerocystic or polycystic or degeneration)).tw. (76)

6 or/1-5 (13885)

7 exp metformin/ (7654)

8 metformin.tw. (10249)

9 (dimethylbiguanidium or dimethylguanylguanidine or glucophage or glucovance).tw. (112)

10 or/7-9 (11652)

11 exp fertilization in vitro/ (28847)

12 (ivf or icsi).tw. (19896)

13 (in vitro fertil\$ or ((intracytoplasmic or intra-cytoplasmic) adj sperm\$)).tw. (21463)

14 exp embryo transfer/ or exp sperm injections, intracytoplasmic/ (16614)

15 or/11-14 (42331)

166 and 10 and 15 (85)

17 randomized controlled trial.pt. (397392)

18 controlled clinical trial.pt. (90499)

19 randomized.ab. (316865)

20 placebo.tw. (167401)

21 clinical trials as topic.sh. (175872)

22 randomly.ab. (227168)

23 trial.ti. (137785)

24 (crossover or cross-over or cross over).tw. (63575)

25 or/17-24 (977646)

26 exp animals/ not humans.sh. (4078006)

2725 not 26 (901386)

2816 and 27 (32)

\section{Database: EBM Reviews - Cochrane Central Register of Controlled Trials <September 2014>}

\section{Search strategy}

1 exp Polycystic Ovary Syndrome/ (772)

2 Polycystic Ovar\$.tw. (1234)

3 (PCOS or PCOD).tw. (924)

4 (stein-leventhal or leventhal).tw. (8)

5 (ovar\$ adj (scelerocystic or polycystic or degeneration)).tw. (3)

6 or/1-5 (1380) 
7 exp metformin/ (1414)

8 metformin.tw. (2235)

9 (dimethylbiguanidium or dimethylguanylguanidine or glucophage or glucovance).tw. (30)

10 or/7-9 (2314)

11 exp fertilization in vitro/ (1616)

12 (ivf or icsi).tw. (2552)

13 (in vitro fertil\$ or ((intracytoplasmic or intra-cytoplasmic) adj sperm\$)).tw. (1822)

14 exp embryo transfer/ or exp sperm injections, intracytoplasmic/ (1055)

15 or/11-14 (3438)

166 and 10 and 15 (38)

\section{Database: EMBASE via Elsevier <1980 to 20 October 2014>}

\section{Search strategy}

1 exp ovary polycystic disease/ (17456)

2 polycystic ovar\$.tw. (14017)

3 (PCOD or PCOS).tw. (9383)

4 (stein-leventhal or leventhal).tw. (651)

5 (ovar\$ adj (scelerocystic or polycystic or degeneration)).tw. (72)

6 or/1-5 (19952)

7 exp METFORMIN/ (35310)

8 metformin.tw. (16359)

9 (dimethylbiguanidium or dimethylguanylguanidine or glucophage or glucovance).tw. (1531)

10 or/7-9 (36285)

11 exp fertilization in vitro/ (39133)

12 (ivf or icsi).tw. (29725)

13 in vitro fertil\$.tw. (21547)

14 ((intracytoplasmic or intra-cytoplasmic) adj sperm\$).tw. (6773)

15 exp intracytoplasmic sperm injection/ (13023)

16 exp embryo transfer/ (21002)

17 or/11-16 (61145)

186 and 10 and $17(321)$

19 Clinical Trial/ (834564)

20 Randomized Controlled Trial/ (351271)

21 exp randomization/ (63592)

22 Single Blind Procedure/ (18900)

23 Double Blind Procedure/ (115714)

24 Crossover Procedure/ (40361)

25 Placebo/ (246816)

26 Randomi?ed controlled trial\$.tw. (104177)

27 Rct.tw. (14914)

28 random allocation.tw. (1341)

29 randomly allocated.tw. (20881)

30 allocated randomly.tw. (1949)

31 (allocated adj2 random).tw. (717)

32 Single blind\$.tw. (14712)

33 Double blind\$.tw. (143861)

34 ((treble or triple) adj blind\$).tw. (395)

35 placebo\$.tw. (202854)

36 prospective study/ (263230)

37 or/19-36 (1388883)

38 case study/ (28194)

39 case report.tw. (265152)

40 abstract report/ or letter/ (903050)

41 or/38-40 (1190552)

4237 not $41(1350817)$

4318 and $42(155)$ 


\section{Database: LILACS <1982 to 2014>}

\section{Search strategy}

((MH:C04.182.612.765\$) OR (MH:C13.351.500.056.630.580.765\$) OR (MH:C19.391.630.580.765\$) OR (TW:"Polycystic Ovary Syndrome") OR (TW:"Síndrome del Ovario Poliquístico") OR (TW:"Síndrome do Ovário Policístico") OR (TW:"Stein-Leventhal Syndrome") OR (TW:"Síndrome de Stein-Leventhal") OR (TW:stein-leventhal) OR (TW:leventhal) OR (TW:PCOS) OR (TW:PCOD) OR (TW:Ovar\$ AND (Poliquístico OR Sclerocystic OR Polycystic OR Degeneration OR Policístico OR Degeneração))) AND ((MH:D02.078.370.141.450\$) OR (TW:Metformin) OR (TW:METFORMINA) OR (TW:Dimethylguanylguanidine) OR (TW:"Dimetil Guanil Guanidina") OR (TW:Dimetilguanilguanidina) OR (TW:Glucophage) OR (TW:Glucovance)) AND ((MH:E02.875.800.500\$) OR (MH:E05.820.800.500\$) OR (TW:Embryo Transfer) OR (TW:Transferencia de Embrión) OR (TW:Transferência Embrionária) OR (TW:Blastocyst Transfer) OR (TW:Tubal Embryo Transfer) OR (TW:Transferencia de Blastocitos) OR (TW:Transferencia Tubaria del Embrión) OR (TW:Transferência de Blastócitos) OR (TW:Transferência Tubária de Embrião) OR (TW:Transferência de Embrião) OR (MH:E02.875.800.750\$) OR (MH:E05.820.800.750\$) OR (TW:Fertilization in Vitro) OR (TW:Fertilización In Vitro) OR (TW:Fertilização In Vitro) OR (TW:Test-Tube Fertilization) OR (TW:Fecundación In Vitro) OR (TW:Fecundación en Probeta) OR (TW:Fertilización en Probeta) OR (TW:Fecundação In Vitro) OR (TW:Fecundação em Tubo de Ensaio) OR (TW:Fertilização em Tubo de Ensaio) OR (MH:E02.875.800.750.700\$) OR (MH:E05.820.800.750.700\$) OR (TW:Inyecciones de Esperma Intracitoplasmáticas) OR (TW:Injeções de Esperma Intracitoplásmicas) OR (TW:Intracytoplasmic Sperm Injections) OR (TW:ICSI) OR (TW:Inyecciones Intracitoplasmáticas de Esperma) OR (TW:IICE) OR (TW:Injeções Intracitoplásmicas de Esperma) OR (TW:assisted reproductive technique) OR (TW:in vitro fertilization) OR (TW:in vitro fertilisation) OR (TW:FIV) OR (TW:IVF))

\section{WHAT'S NEW}

\begin{tabular}{lll}
\hline Date & Event & Description \\
\hline 16 April 2015 & Amended & $\begin{array}{l}\text { Correction of text error in Abstract and Plain language summary, } \\
\text { and addition of search result numbers in Appendix 1. }\end{array}$ \\
\hline
\end{tabular}

\section{H I S T O R Y}

Protocol first published: Issue 3, 2006

Review first published: Issue 2, 2009

\begin{tabular}{lll}
\hline Date & Event & Description \\
\hline 15 October 2014 & New search has been performed & $\begin{array}{l}\text { One new co-author was added for the update of this review (Cris- } \\
\text { tiane R Macedo). } \\
\text { Three new trials were added. }\end{array}$ \\
\hline 15 October 2014 & $\begin{array}{l}\text { New citation required and conclusions } \\
\text { have changed }\end{array}$ & $\begin{array}{l}\text { With the addition of three new studies (Kjotrod 2011; Palomba } \\
2011 ; \text { Qublan 2009), totalling 816 participants, the conclusions of } \\
\text { the review have changed. }\end{array}$ \\
\hline
\end{tabular}

1 November $2012 \quad$ New search has been performed

The search was updated on 5 November 2012.

Three new trials were included (Kjotrod 2011; Palomba 2011; Qublan 2009) totalling 801 participants. The conclusions of the review changed: the clinical pregnancy rate was significantly higher in the metformin group.

Two new co-authors were added (Luiz Eduardo T Albuquerque and Cristiane R Macedo).

\begin{tabular}{lll}
\hline 31 August 2008 & Amended & The 'Risk of bias' table was completed. \\
\hline 13 April 2008 & Amended & The review was converted to the new format. \\
\hline
\end{tabular}




\begin{tabular}{lll}
\hline Date & Event & Description \\
\hline 28 February 2008 & $\begin{array}{l}\text { New citation required and conclusions } \\
\text { have changed }\end{array}$ & Substantive amendment. \\
\hline
\end{tabular}

\section{CONTRIBUTIONS OF AUTHORS}

For the present update of this review:

- CRM: revised and updated the review.

- LT: revised and updated the review.

- MFC: revised and updated the review.

- LA: revised and updated the review.

- RA: revised and updated the review.

For the protocol and review.

- LA: initiated and conceptualised the protocol and the initial version of the review.

- RA: initiated and conceptualised the protocol and the initial version of the review.

- MFC: contributed to the protocol and the initial version of the review.

- VF: contributed to the protocol and the initial version of the review.

- LT: contributed to the protocol and the initial version of the review.

\section{DECLARATIONS OF INTEREST}

Review author Dr Michael Costello is a member of the pharmaceutical company Merck Sharp and Dohme (MSD) Australia Elonva Advisory Board Committee. He has received funding to attend ART Scientific Meetings including to present papers not on the review topic. These relationships are declared in the interests of transparency and do not constitute a conflict of interest in this review.

\section{SOURCES OF SUPPORT}

\section{Internal sources}

- Federal University of São Paulo (UNIFESP/EPM), Brazil.

\section{External sources}

- Nuffield Department of Obstetrics and Gynecology, UK.

- School of Women's and Children's Health, Division of Obstetrics and Gynecology, Royal Hospital for Women, Australia.

\section{DIFFERENCES BETWEEN PROTOCOLANDREVIEW}

The following outcomes were in the original protocol and have since been removed: clinical pregnancy rate (per transfer), pregnancy rate (per transfer and per woman), number of follicles and embryo quality (Methods; Types of outcome measures). Absolute risk was calculated for the primary outcomes.

After the publication of the protocol we decided to stratify the main analysis by type of stimulation protocol used (long GnRH-agonist or short GnRH-antagonist), in order to determine whether the type of stimulation used had an influence on the outcomes.

\section{N DEX TERMS}

\section{Medical Subject Headings (MeSH)}

*Fertilization in Vitro; *Live Birth; Hyperandrogenism [ ${ }^{*}$ drug therapy]; Hyperinsulinism [ ${ }^{\star}$ drug therapy]; Hypoglycemic Agents [ ${ }^{\star}$ therapeutic use]; Metformin [ ${ }^{*}$ therapeutic use]; Polycystic Ovary Syndrome [ ${ }^{\star}$ complications]; Pregnancy Rate; Randomized Controlled Trials as Topic; Sperm Injections, Intracytoplasmic

\section{MeSH check words}

Female; Humans; Pregnancy 